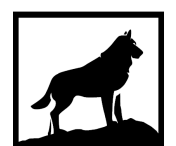

Michigan

Technological

1 8 8 5 University
Michigan Technological University

Digital Commons @ Michigan Tech

EFFECT OF DEVELOPMENT OF SCANDIUM TRIALUMINIDE PRECIPITATES ON CORROSION AND MECHANICAL BEHAVIOR IN ALUMINUM-MAGNESIUM ALLOYS

Carson Williams

Michigan Technological University, cfwillia@mtu.edu

Copyright 2019 Carson Williams

Recommended Citation

Williams, Carson, "EFFECT OF DEVELOPMENT OF SCANDIUM TRIALUMINIDE PRECIPITATES ON CORROSION AND MECHANICAL BEHAVIOR IN ALUMINUM-MAGNESIUM ALLOYS", Open Access Master's Thesis, Michigan Technological University, 2019.

https://doi.org/10.37099/mtu.dc.etdr/905

Follow this and additional works at: https://digitalcommons.mtu.edu/etdr

Part of the Metallurgy Commons 


\title{
EFFECT OF DEVELOPMENT OF SCANDIUM TRIALUMINIDE PRECIPITATES ON CORROSION AND MECHANICAL BEHAVIOR IN ALUMINUM-MAGNESIUM ALLOYS
}

\section{By}

Carson Foster Williams

\begin{abstract}
A THESIS
Submitted in partial fulfillment of the requirements for the degree of MASTER OF SCIENCE

In Materials Science and Engineering
\end{abstract}

MICHIGAN TECHNOLOGICAL UNIVERSITY

2019

(C) 2019 Carson Foster Williams 

This thesis has been approved in partial fulfillment of the requirements for the Degree of MASTER OF SCIENCE in Materials Science and Engineering.

Department of Materials Science and Engineering

\author{
Thesis Advisor: $\quad$ Dr. Paul Sanders \\ Committee Member: $\quad$ Dr. Stephen Kampe \\ Committee Member: $\quad$ Dr. Daniel Seguin \\ Department Chair: $\quad$ Dr. Stephen Kampe
}





\section{Contents}

Acknowledgements ........................................................................................................... vii

Abstract................................................................................................................................ viii

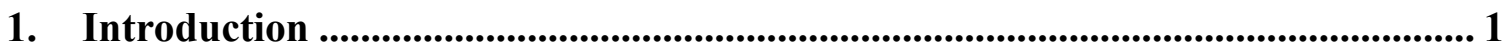

1.1 Aluminum Alloys ................................................................................... 1

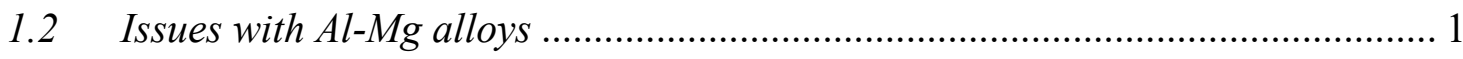

2. Background .......................................................................................................... 3

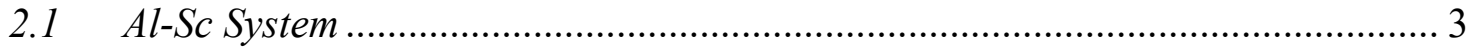

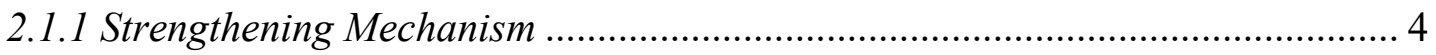

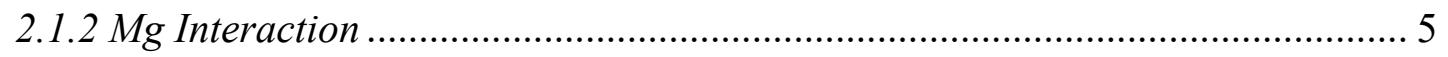

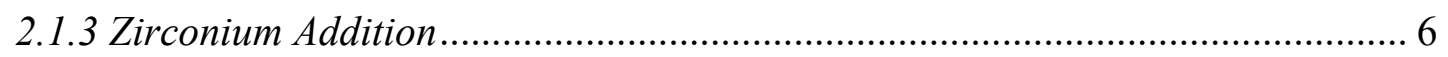

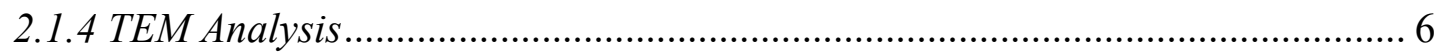

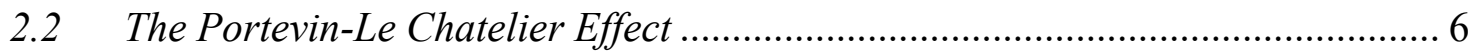

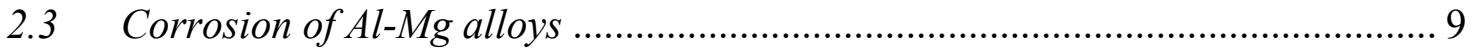

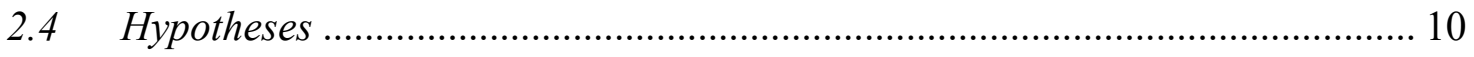

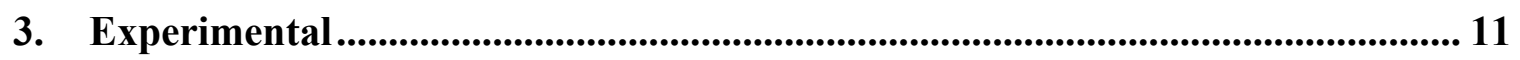

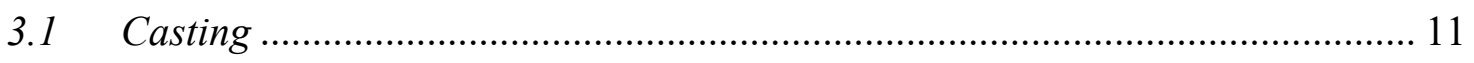

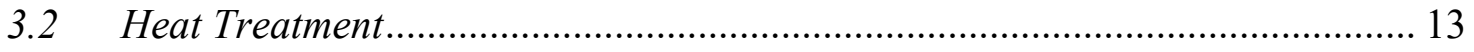

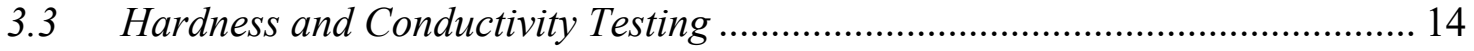

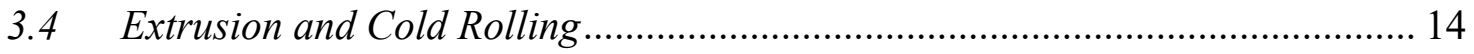

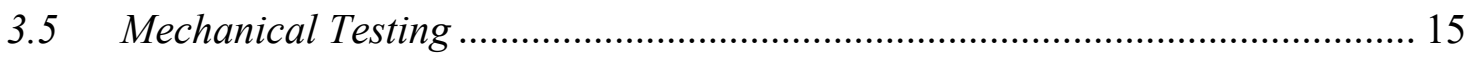

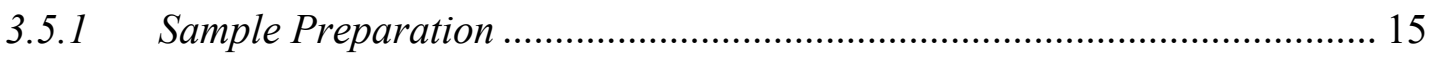

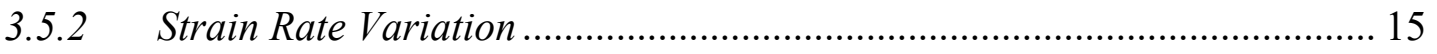

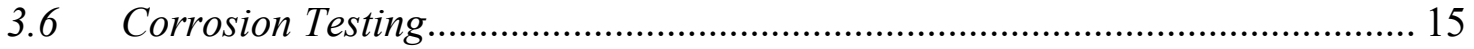

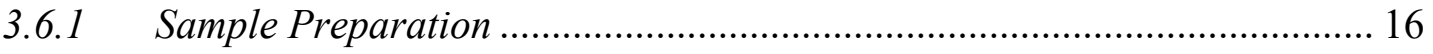

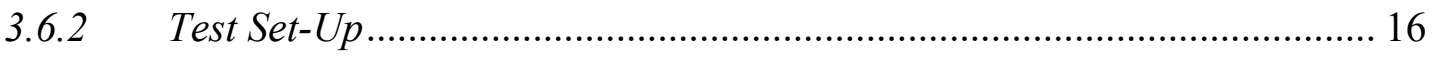

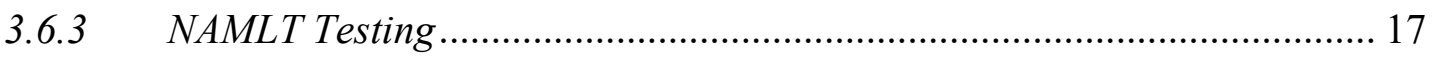

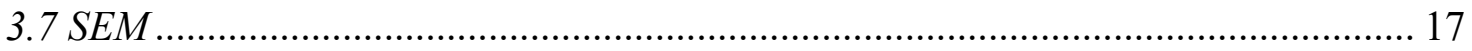

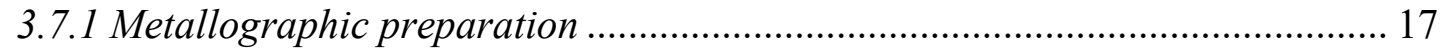

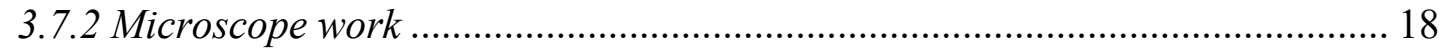




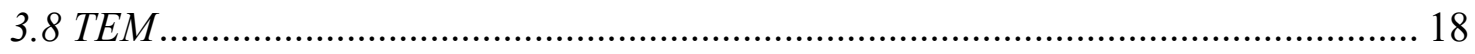

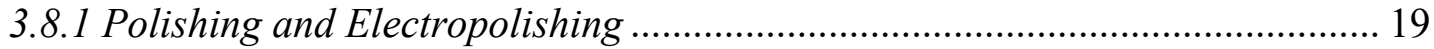

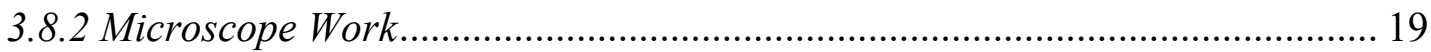

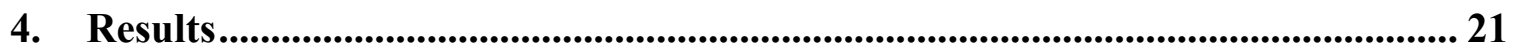

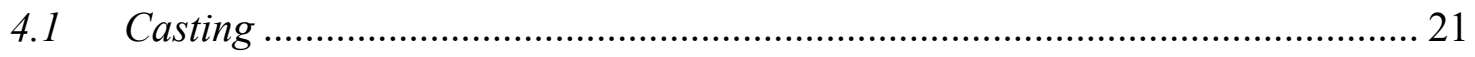

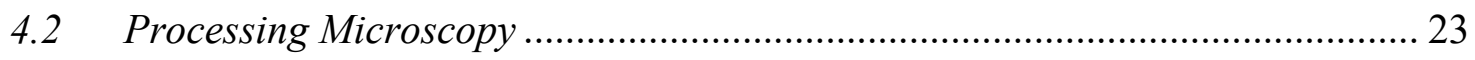

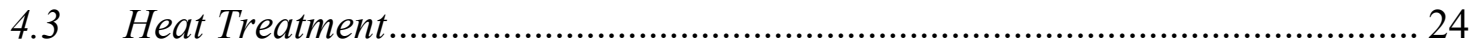

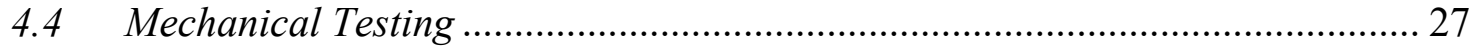

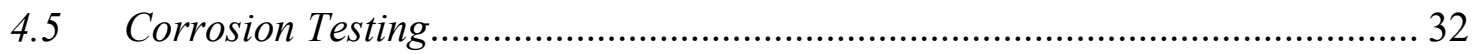

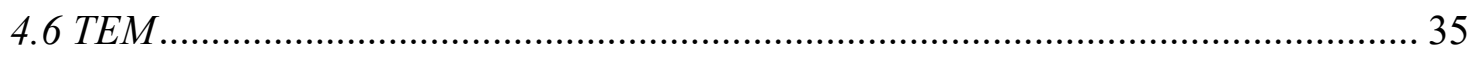

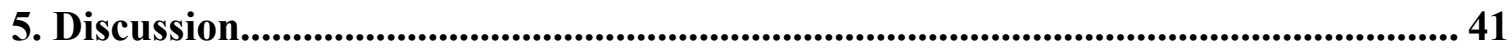

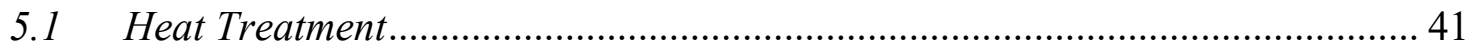

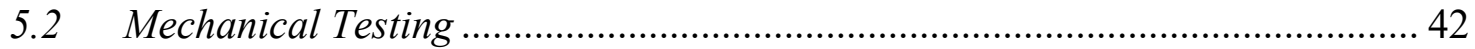

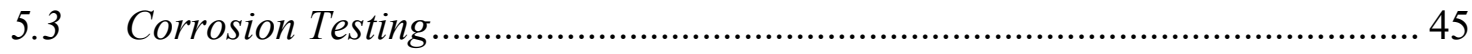

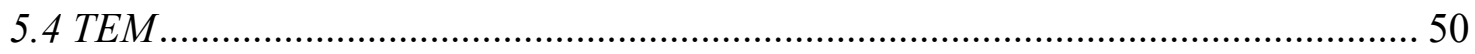

6. Conclusions ........................................................................................................................... 55

References........................................................................................................... 57 


\section{Acknowledgements}

I would like to acknowledge Dr. Paul Sanders for his advisement for the duration of this work. His insight, lessons, and help with aluminum metallurgy, research methodology and technique, professional conduct and scientific fundamentals were invaluable to me as a student and researcher.

I would also like to acknowledge Timothy Langan and Clean Teq for their monetary support of this work, as well as experience, knowledge, and expertise in the many facets of this research project.

The transmission electron microscopy research was performed at Deakin Advanced Characterisation Facility at Deakin University in Victoria, Australia.

The scanning electron microscopy research was performed at the Applied Chemical and Morphological Analysis Laboratory, at Michigan Technological University. Electron microscopy facility is supported by NSF MRI 1429232.

I would like to thank many of the MSE department staff as well for their assistance and guidance throughout this project: Tom Wood and Russ Stein provided guidance and help in the casting, extrusion, processing of material for my research, and provided guidance and knowledge on the many processes throughout. Tom Wood was also crucial in my development as a metallurgist, understanding of the different aluminum alloy principles and understanding the metallurgical development throughout my work. Paul Fraley provided help and training in testing processes, hardware, and technique. Gerry Anzalone provided support on SEM studies and preparation and understanding of different SEM techniques. Dr. Daniel Seguin and Dr. Pinaki Mukherjee operated the TEM and STEM scopes throughout my project that helped me develop the knowledge and understanding necessary of my project.

I would also like to thank the MSE family of students for their help with understanding of metallurgical principles and knowledge. Avishan Arab Shomali was very helpful with sample preparation for STEM work. I would especially like to acknowledge Phil Staublin for his insight into the many different problems that arose throughout my work, conversation and scientific understanding, and for his help with coding and metallographic preparation.

Lastly, I would like to thank my parents, Jeanne and Craig, for their support of my college career over the last several years, and my brother and sister, Cole and Castyn, for lending a listening ear when I faced struggles and challenges. 


\begin{abstract}
Development of aluminum alloys has seen an increase in attention in recent years. The $5 \mathrm{xxx}$ series of Al-Mg alloys has the potential to provide strong, lightweight materials in various industry applications, however issues with strain formability and corrosion hinder the development of these alloys. The addition of $\mathrm{Sc}$ for developing $\mathrm{Al}_{3} \mathrm{Sc}$ precipitates provides considerable precipitation strengthening as well as grain refinement characteristics that can help mitigate these issues. Alloys with varied Mg content were analyzed for heat treatment aging responses and precipitate formation, changes in mechanical behavior related to the Portevin-le Chatelier effect, and effects on intergranular corrosion when tested with and without inclusion of $\mathrm{Al}_{3} \mathrm{Sc}$ precipitates. Findings are presented that show similarities in aging response, differences in precipitate formation, alterations in the severity and type of strain instability during deformation, and mitigation of intergranular corrosion.
\end{abstract}




\section{Introduction}

\subsection{Aluminum Alloys}

Aluminum alloys provide opportunities for lightweight products in many applications, particularly in structural applications that traditionally use heavier metals such as steel or cast iron. Furthermore, aluminum alloys and their properties can be varied and tailored for specific applications with a variety of major and minor alloying elements, with different alloy "series" existing based on the principal alloying element. A common desire is to increase strength properties through different methods, such as precipitation or solid solution strengthening. Of the elements used for the latter, magnesium is particularly potent for increasing strength in aluminum alloys, with Al-Mg alloys consisting the $5 \mathrm{xxx}$ alloy series. Magnesium is highly soluble in aluminum as a substitutional element within the aluminum matrix, so a large amount of $\mathrm{Mg}$ can be added to achieve high strengths in 5xxx series alloys. However, increasing Mg content in these alloys can cause issues with formability and corrosion that can hinder the use of the strong material.

\subsection{Issues with Al-Mg alloys}

A risk of increasing $\mathrm{Mg}$ content in aluminum alloys is the issue of intergranular corrosion caused by $\mathrm{Mg}$ concentrations at grain boundaries [1,2]. One of the most accessible ways for this to happen is through a process known as sensitization, in which an $\mathrm{Al}_{3} \mathrm{Mg}_{2}$ phase ( $\beta$-phase) forms along grain boundaries [1,2]. A phase diagram of the binary $\mathrm{Al}-\mathrm{Mg}$ system is shown in Figure 1. 


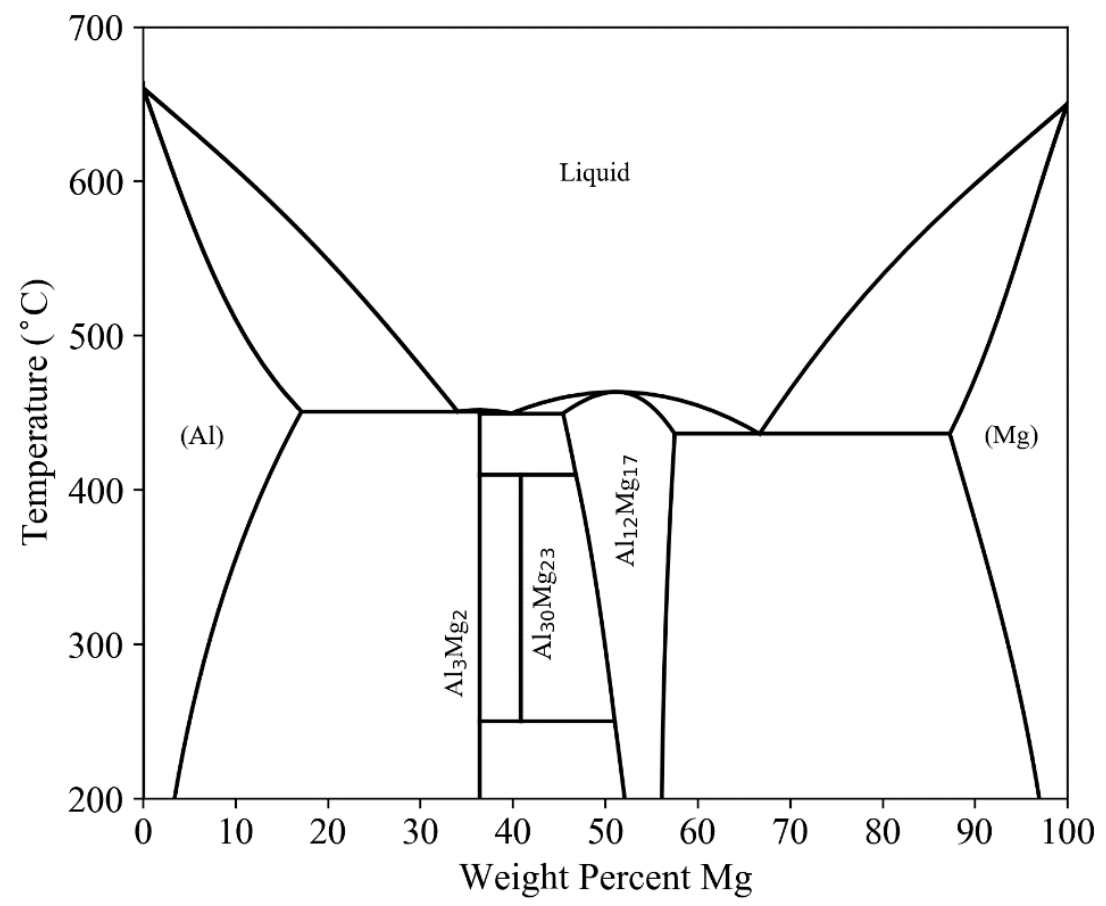

Figure 1. Binary Al-Mg phase diagram. Selected single-phase regions are labelled.

From the phase diagram, the solubility of $\mathrm{Mg}$ in the aluminum matrix is quite high, allowing for a significant of solid solution strengthening. However, continually increasing the $\mathrm{Mg}$ solute content increases the risk of sensitization. During sensitization, the $\beta$-phase forms continuously along grain boundaries leading to much higher corrosion susceptibility. Forcing the $\beta$-phase to form discreetly through a heat treat process known as stabilization can help prevent sensitization during the service life of 5xxx series aluminum alloys.

Another notable issue with Al-Mg issues is stress-strain instability during forming operations. Present in many solid-solution strengthened alloys is the Portevin-Le Chatelier (PLC) effect. This phenomenon, which is related to the dynamic strain aging effect, arises from immobile obstacles in the alloy matrix blocking the motion of dislocations during plastic deformation of the material, which lead to heterogeneities in the stress-strain behavior [3]. Physically, visible bands can form on the surface of materials susceptible to the PLC effect, which has adverse effects on the applications of certain alloys in appearance-critical applications, as well as hindering the physical properties of the material. 


\section{Background}

\subsection{Al-Sc System}

Additions of scandium to aluminum alloys allow for the formation of $\mathrm{Al}_{3} \mathrm{Sc}$ precipitates, during solidification and via subsequent heat treatment. These precipitates vary in size depending on processing conditions and ternary alloying elements but are generally formed on the order of 2-50 $\mathrm{nm}[4,5]$. A large body of work has been conducted on the binary Al-Sc system and on more complex alloy systems involving Sc, focusing on precipitate formation, morphology, property effects, etc. From this work, a growing understanding of the Al-Sc alloy system has been and is being developed.

In aluminum alloys, the typical matrix phase of a given alloy forms a face-centered cubic (FCC) crystal lattice, with each unit cell consisting of 4 atoms. In the case of the $\mathrm{Al}_{3} \mathrm{Sc}$ secondary phase, the precipitates form in the $\mathrm{L}_{2}$ crystal structure, in which one $\mathrm{Al}$ atom per FCC unit cell is replaced with a Sc atom. Due to this similarity in structure, the $\mathrm{L}_{2}$ phase is highly ordered within the FCC crystal lattice, which reduces the incoherency effects that can be present in precipitate phase, especially when precipitate size is kept relatively small [5]. The increase in coherency of the precipitates increases the strengthening benefits associated with them.

One of the major issues in the Al-Sc system is that $\mathrm{Sc}$ has a very low solubility in aluminum alloys. This lack of solubility limits the extent to which $\mathrm{Al}_{3} \mathrm{Sc}$ precipitates can be formed. In the casting of Al-Sc alloys, upon solidification the alloy forms a supersaturated Al-Sc matrix. During heat treatment, the Sc is removed from solution to form $\mathrm{Al}_{3} \mathrm{Sc}$ precipitates. However, as increasing amounts of $\mathrm{Sc}$ are added to the cast material, primary precipitates may form during solidification. A partial phase diagram of the Al-Sc binary system focusing on the $\mathrm{Al}_{3} \mathrm{Sc}$ eutectic region is shown in Figure 2. 


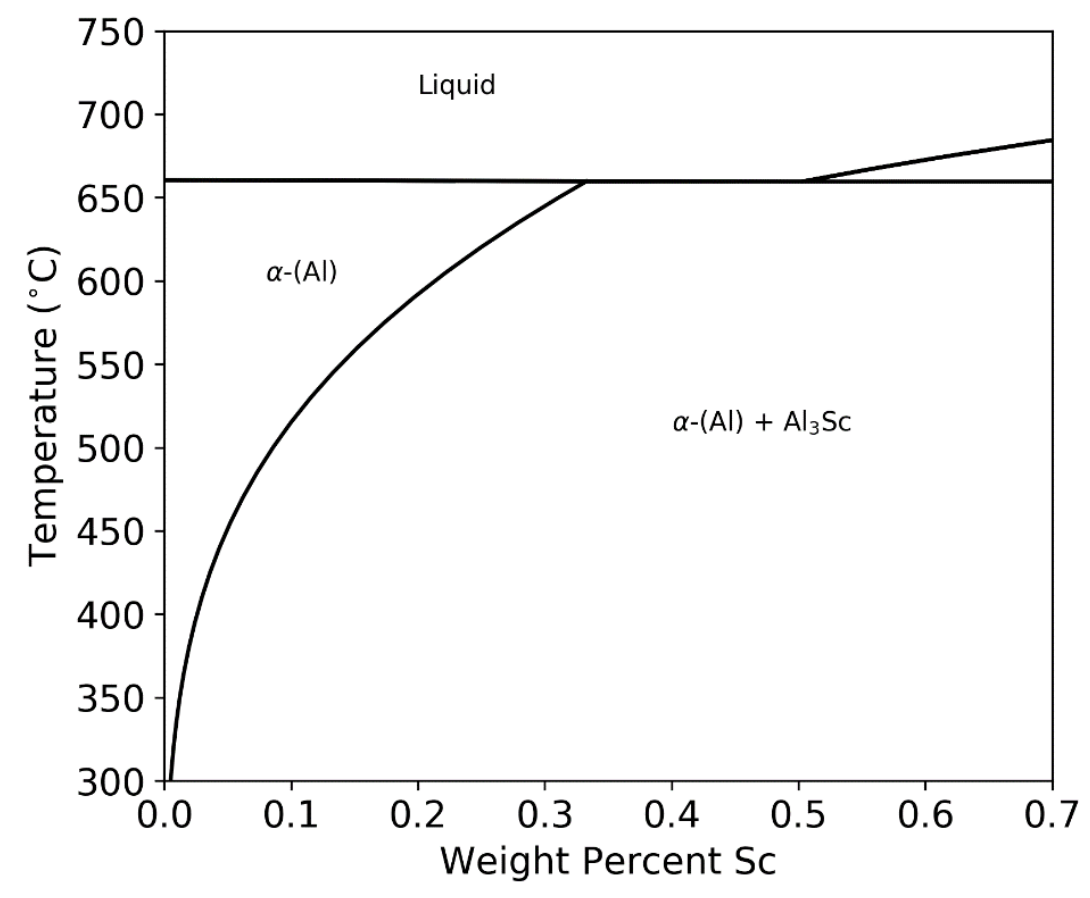

Figure 2. Partial Al-Sc phase diagram showing $\mathrm{Al}_{3} \mathrm{Sc}$ eutectic region. Labels indicate equilibrium phases.

The Al-Sc phase diagram shows that equilibrium solubility of Sc approaches almost zero at low temperatures, necessitating the solid solution of $\mathrm{Sc}$ for precipitation to occur under heat treatment.

Due to the high cost of Sc as an alloying addition, too large of additions can lead to expensive materials without returning mechanical benefits. Therefore, it is often desirable to maintain a relatively low Sc content in Al-Sc alloys, particularly those with any commercial use.

\subsubsection{Strengthening Mechanism}

There are two distinct mechanisms involved with precipitation strengthening of metals. The first is particle cutting, in which mobile dislocation lines cut through the particles (precipitates). The second is Orowan strengthening, in which particles are too large to be cut and instead dislocation loops are formed around precipitates by moving dislocation lines [6]. The total strengthening contribution from precipitate structures comes from the minimization of the two mechanisms. Therefore, as precipitates increase in size, strengthening from the cutting mechanism is lost and Orowan strengthening is active [6, 7]. The equations for cutting and Orowan strengthening are given in equations 2.1 and 2.2 , respectively [6], [8].

$$
\Delta \sigma_{\text {cutting }}=0.44 * M * G_{A l_{3} S C} * \frac{\gamma_{A P B}}{b} * f^{1 / 2}
$$




$$
\Delta \sigma_{\text {Orowan }}=\frac{0.4 * M * G_{M} * b * \ln \left(\frac{2 \bar{R}}{b}\right)}{\pi * \lambda_{e-e^{*} \sqrt{1-v_{M}}}}
$$

Where $\mathrm{M}$ is the Taylor factor for this system, $\mathrm{G}$ values are shear moduli of the matrix and the precipitates, $\mathrm{b}$ is the Burger's vector, $\mathrm{R}$ is the average particle radius, $\bar{R}=\frac{\pi}{4} R, \mathrm{f}$ is the precipitate volume fraction, $v_{\mathrm{n}}$ is the Poisson's ratio of the aluminum matrix, and $\gamma_{\mathrm{APB}}$ is the anti-phase boundary energy associated with shearing or cutting of the precipitates. Finally, $\lambda_{\text {e-e }}$ is the edge-to-edge spacing of the $\mathrm{Al}_{3} \mathrm{Sc}$ precipitates in the matrix, calculated by equation $2.3[6],[8],[9]$.

$$
\lambda_{e-e}=R *\left(\left(\frac{2 \pi}{3 f}\right)^{1 / 2}-\frac{\pi}{2}\right)
$$

From this set of equations, the strength contribution is proportional to the volume fraction of precipitates, and as precipitate radius increases, the Orowan strengthening increment decreases. This explains the take-over of Orowan strengthening as the primary strengthening mechanism at large precipitate radii. In the case of $\mathrm{Al}_{3} \mathrm{Sc}$ precipitates, cutting or order strengthening loses dominance above radii of about $1-3 \mathrm{~nm}$ [10]. Particles of larger radii provide strengthening predominantly through the Orowan mechanism.

\subsubsection{Mg Interaction}

The presence of $\mathrm{Mg}$ in aluminum alloys may affect the precipitation behavior of the $\mathrm{Al}_{3} \mathrm{Sc}$ secondary phase [6 - 8]. Increasing amount of Mg solute content decreases the solubility of Sc in Al. A plot of the decreasing solubility of Sc as a function of $\mathrm{Mg}$ content, produced by ThermoCalc material modeling software, is shown in Figure 3.

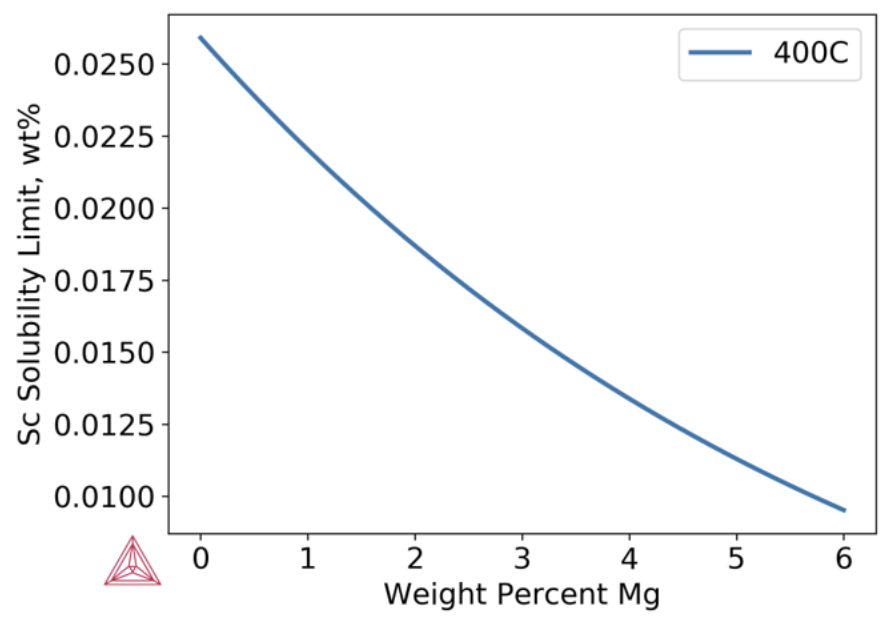

Figure 3. Solubility of $\mathrm{Sc}$ in $\mathrm{Al}$ at $400 \mathrm{C}$ as a function of $\mathrm{Mg}$ content

As increasing $\mathrm{Mg}$ content is added to an alloy, the equilibrium solubility diminishes. A consequence of this is that the risk of primary precipitate formation during 
solidification is increased. However, if all Sc content is able to remain in solution during solidification, then the equilibrium amount of $\mathrm{Al}_{3} \mathrm{Sc}$ is accordingly increased. As a result, total volume fraction of precipitates would be increased.

While increasing $\mathrm{Mg}$ content affects the overall volume fraction of $\mathrm{Al}_{3} \mathrm{Sc}$ precipitates, there is no clear agreement as to whether the presence of $\mathrm{Mg}$ enhances the formation of the precipitates. Potential enhancement could arise from solute clusters facilitating nucleation sites, or from increased strain energy due to solid solution providing driving force for formation of secondary phases similar to adding energy for recrystallization. The ambiguity of the effect of $\mathrm{Mg}$ on $\mathrm{Al}_{3} \mathrm{Sc}$ precipitation is one of the questions that is sought to be answered by this work.

\subsubsection{Zirconium Addition}

A common alloying addition in Al-Sc alloys is zirconium. The thermodynamically stable crystal structure of this secondary phase is the tetragonal $\mathrm{D}_{23}$ structure, but $\mathrm{Al}_{3} \mathrm{Zr}$ will form the metastable $\mathrm{L}_{2}$ crystal structure shared with $\mathrm{Al}_{3} \mathrm{Sc}$ precipitates $[4,13]$. The $\mathrm{Al}_{3} \mathrm{Zr}$ phase forms and coarsens at significantly higher heat treatment temperatures than the $\mathrm{Al}_{3} \mathrm{Sc}$ phase. Additionally, when the $\mathrm{Al}_{3} \mathrm{Sc}$ precipitates are formed before the $\mathrm{Al}_{3} \mathrm{Zr}$ precipitates, the latter tends to form a shell around the former, leading to a "core-shell" precipitate structure [4], [9]. The $\mathrm{Al}_{3} \mathrm{Zr}$ shell prevents coarsening of the $\mathrm{Al}_{3} \mathrm{Sc}$ precipitates, so that the precipitate microstructure is more stable at elevated temperatures.

\subsubsection{TEM Analysis}

As was noted, the $\mathrm{Al}_{3} \mathrm{Sc}$ precipitates that form in these aluminum alloys generally form in the $2-50 \mathrm{~nm}$ size range $[4,5]$, sufficiently small that analysis via more traditional microscopy methods (optical, scanning electron microscopy) is not a viable option. In order to analyze the size and distribution of precipitates, transmission electron microscopy (TEM) must be used. TEM uses a charged electron beam to pass through the material being analyzed, and can be used to collect data on dislocation formations, crystal diffraction, compositional information, strain contrasts, etc. More importantly, brightfield images of precipitates can be relatively easily obtained, and focusing on the specific diffraction patterns of the $\mathrm{L}_{2}$ structured precipitates enables darkfield imaging. Both of these techniques are important in this work for analysis of the size and distribution of the $\mathrm{Al}_{3} \mathrm{Sc}$ precipitates.

\subsection{The Portevin-Le Chatelier Effect}

As mentioned in section 1.2, many solid solution strengthened aluminum alloys suffer from what is known as the PLC effect during plastic deformation, which is based around the dynamic strain aging (DSA) model. Therefore, understanding the PLC effect necessitates an understanding of the DSA model. During plastic deformation of metals, mobile dislocations move through the crystal lattice. However, as the dislocations travel, they interact with immobile barriers, such as solute atoms or clusters, immobile dislocations, precipitates, etc. $[3,10]$. When a dislocation becomes pinned by some 
obstacle, a field of strain energy is generated and grows as stress is continually applied to the material. This strain field provides a driving force for diffusion of solute atoms toward the halted dislocation. These solute atoms then aid in the pinning of the dislocation Eventually, as stress is continually applied to the material, enough energy builds up that the dislocation becomes unpinned, until it is pinned by some other obstacle further along, and the process repeats $[3,6]$. This model gives rise to the more specific PLC effect in aluminum alloys. A graphical representation of the DSA model is shown in Error! Reference source not found.Figure 4.
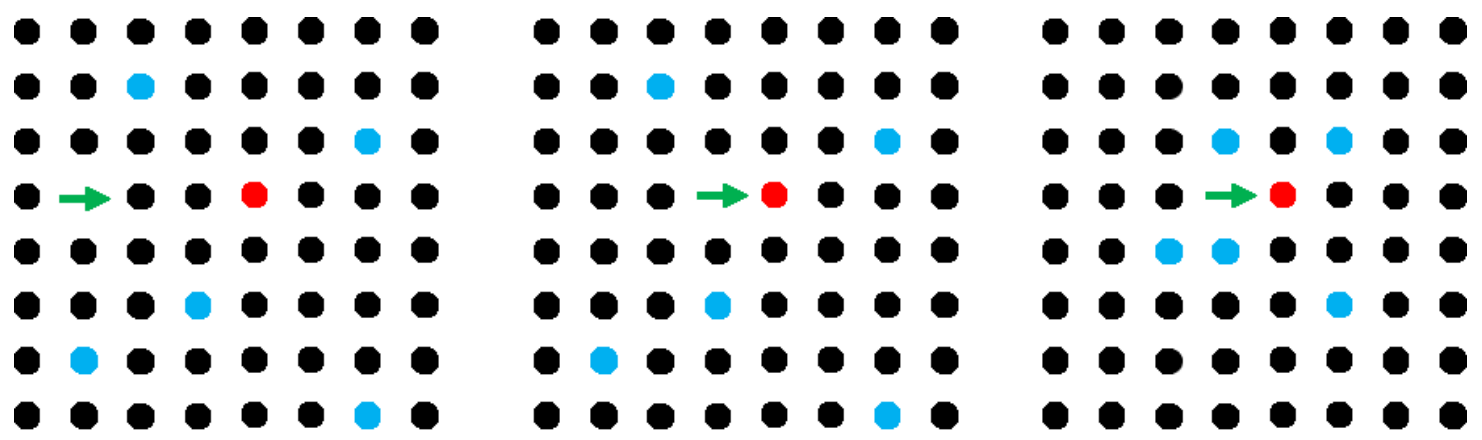

- Matrix atom

- Solute atom

- Dislocation impediment

Figure 4. Graphical representation of the dynamic strain aging model. As a dislocation, represented by the green arrow, travels through the crystal lattice and is pinned by some obstacle, shown in orange, solute atoms diffuse toward the dislocation.

The speed of solute atom diffusion dictates the exact type of behavior that results from dynamic strain aging. When solute atoms diffuse slowly, the solute diffusion after forming, rather than during, and concentrations of solute atoms pin dislocations after time. This is generally linked to the phenomenon of Lüders bands and yield decrease commonly seen in steels [6]. However, as diffusivity of solute atoms increases, the solute atoms are able to diffuse to dislocation pinning sites as soon as pinning occurs. This leads to a periodic pinning and unpinning of dislocations that results in the serrated plastic flow associated with the Portevin-le Chatelier (PLC) effect [3], [6]. Further increases of diffusivity, for example when the solute atoms occupy interstitial sites rather than substitutional, result in diffusion that accompanies dislocation movement without pinning, and serrated flow, as well as apparent yield point, is lost [6]. In the case of Al$\mathrm{Mg}$ alloys, diffusivity is such that the PLC effect is relevant.

Particular to the PLC effect is a characteristic stress banding that occurs, wherein the stress pileups and releases explained in the DSA model form as bands along the material, often visible to the naked eye. Additionally, the nature of the PLC effect changes drastically depending on the strain rate applied to the material during deformation. In fact, three distinct behaviors, called Types A, B, and C, occur at varying strain rates, with 
Type A occurring at higher strain rates than the other two and Type $\mathrm{C}$ occurring at the slowest strain rates $[3,11]$. Each behavior is associated with characteristic stress-strain variation behavior, related to the degree and frequency at which dislocations are halted and stress is able to build up and release.

Type A behavior exhibits small stress variations, often occurring in a stepwise fashion, highlighting that not much energy build-up occurs at relatively high strain rates before the halted dislocations are able to move. Type B behavior exhibits a "hack saw" pattern, with stress variations that occur very frequently and are larger in magnitude than in type A behavior. Finally, Type $\mathrm{C}$ behavior is characterized by large stress drops that occur much less frequently than in Type B behavior. When considering the physical banding that occurs on material surfaces of deformed material, each behavior has its own characteristic formation behavior. Type A behavior typically forms propagating bands low in magnitude of stress serration, and as such the bands themselves are not very severe. Type B behavior forms propagating/hopping bands as well, with larger stress serrations than in Type A behavior and therefore more severe. However, the high frequency of the bands causes a regular banding pattern across the material. Type $\mathrm{C}$ behavior forms the most severe bands; static bands representing large stress concentration and release that occur infrequently and are therefore more pronounced on the surface of material [3, 14]. In these regards, when considering the severity of each behavior type, Type $\mathrm{A}$ is considered the least detrimental PLC behavior and Type $\mathrm{C}$ the most detrimental.

In addition to dependence on strain rate, PLC behavior has a temperature effect. It has been explained that the PLC effect is rooted in the DSA model and diffusion of solute atoms to contribute to the pinning and unpinning of dislocations. It was also described that the nature of DSA behavior (Lüders banding, PLC effect, stable flow) is dependent on the relative speed difference between the dislocations and solute atoms [6]. In the case of strain rate variation, the speed of the dislocations is increased or decreased. Under temperature variation, solute diffusivity is increased, and the difference in movement between the solute atoms and dislocations changes accordingly, affecting the DSA behavior [6]. Temperature effects during extrusion and other thermomechanical processing also have effects on dislocation distribution, grain structure, etc. that change the behavior in subsequently formed material.

It is proposed that the development of $\mathrm{Al}_{3} \mathrm{Sc}$ precipitates can have an effect on the PLC behavior observed in Al-Mg alloys. Inclusion of precipitates in Al-Mg alloys provide additional barriers to dislocation motion during deformation [14-16], which in turn effects the pinning and unpinning behavior related to the diffusion of solutes and dislocation motion. It has been explained that the DSA model and subsequently the PLC effect are based on the movement of dislocations and diffusion of solute atoms. Therefore, any effect of precipitates must be on either dislocation movement or solute diffusion. Current work proposes the former is responsible for the alterations in PLC behavior to be analyzed. Previous work involving precipitates in concentrated Al-Mg 
alloys shows inversion of traditionally predicted PLC behavior, particularly with respect to critical strain for PLC onset $[14,15]$ as well as the mode of PLC band formation and propagation [14]. It was explained that Type A and B modes of banding (deemed least severe) form by propagation of bands, whereas Type $\mathrm{C}$ (deemed more detrimental) forms static bands randomly through the material. Based on the DSA model and [14], the addition of coherent $\mathrm{Al}_{3} \mathrm{Sc}$ precipitates adds additional barriers to dislocation motion that allow greater diffusion of solute atoms to pinned dislocations. Consideration in terms of timing of dislocation motion, $\mathrm{t}_{\mathrm{d}}$, and of diffusion of solute atoms and the associated time for unpinning of the dislocation, $t_{w}$, shows that the $t_{w}$ increases in the presence of precipitates [14]. Additionally, the presence of precipitates generates internal stresses that can facilitate plastic flow. The enhanced ability of solute atoms to diffuse to and interact with pinned solute atoms paired with the stresses from precipitates, then, can create a more regular cycle of pinning and unpinning associated with propagating banding rather than static banding. In this sense, the deformation behavior is homogenized through the inclusion of precipitates.

\subsection{Corrosion of Al-Mg alloys}

As noted in section 1.2, a common issue for Al-Mg alloys, particularly at high $\mathrm{Mg}$ content, is the development of high corrosion rates after exposure to elevated service temperatures, particularly in wrought or work-hardened material. In such cases, a process known as sensitization takes place in these alloys. During sensitization, the secondary $\beta$ phase $\mathrm{Al}_{3} \mathrm{Mg}_{2}$ is precipitated from the solid solution and forms a continuous layer along grain boundaries. The $\beta$ phase will corrode much more readily than the solid solution, and therefore the material will lose mass much quicker after sensitization, often with entire grains being lost when the grain boundary has been sufficiently corroded [1,2].

A common method for preventing sensitization or lessen its effect is called stabilization. Similar to sensitization, the aim is to precipitate the $\mathrm{Al}_{3} \mathrm{Mg}_{2}$ phase; however, during stabilization a higher temperature heat treatment is used so the $\beta$ phase forms discreetly rather than continuously along grain boundaries. This process results in energetically favorable non-continuous $\mathrm{Al}_{3} \mathrm{Mg}_{2}$ and reduces the available $\mathrm{Mg}$ in solution that can contribute to later sensitization [2]. A diagram depicting sensitized and stabilized grain boundaries is shown in Figure 5. 


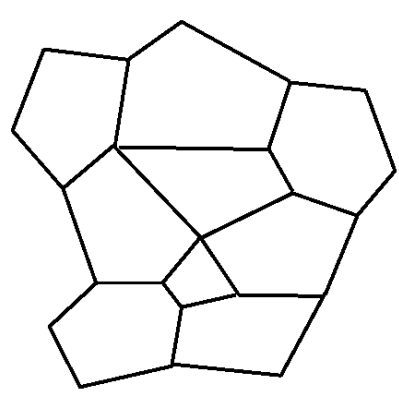

a

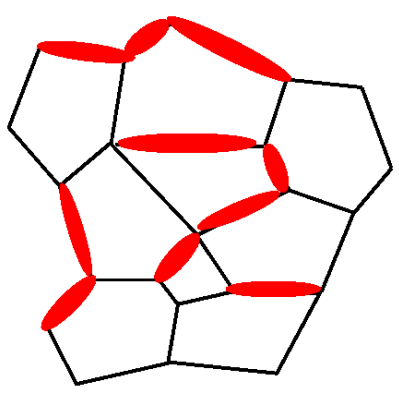

b

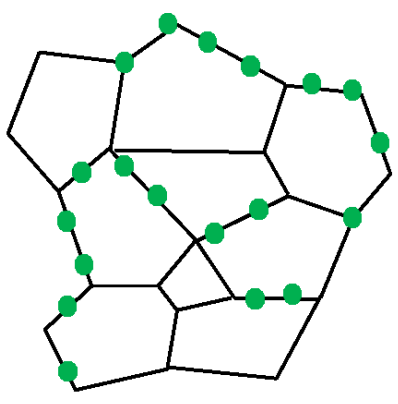

c

Figure 5. Depiction of sensitization and stabilization. a.) Unsensitized grains, grain boundaries shown in black. b.) Sensitized grains. Continuous $\beta$-phase shown in red along grain boundaries. c.) Stabilized grains. Discreet $\beta$-phase shown in green along grain boundaries

Given the issue of sensitization leading to intergranular corrosion, a greater ratio of grain boundary to grain volume, i.e. finer and more numerous grains, can reduce the corrosion effects caused by sensitization, due to the abundance of grain boundary volume that will not be able to be sensitized. At a point during sensitization, there will be insufficient $\mathrm{Mg}$ in solution to continue forming $\mathrm{Al}_{3} \mathrm{Mg}_{2}$, and the larger the grain boundary volume, the more grain boundary that will not have undergone sensitization. It is in this regard that the development of $\mathrm{Al}_{3} \mathrm{Sc}$ precipitates is applicable. The fine dispersoids increase the work-hardening of the Al-Mg alloys, while also acting as grain refiners and preventing recrystallization from heat treatment [17]. As a result, after performing considerable work on the material, $\mathrm{Al}-\mathrm{Mg}$ alloys that have inclusions of $\mathrm{Al}_{3} \mathrm{Sc}$ precipitates have a much finer grain structure than those that do not and are therefore less susceptible to sensitization and the resulting intergranular corrosion.

\subsection{Hypotheses}

The proposed effects of $\mathrm{Al}_{3} \mathrm{Sc}$ precipitates on mechanical behavior and corrosion effects in Al-Mg alloys has led to the development of two different hypotheses:

1: If fine $\mathrm{Al}_{3} \mathrm{Sc}$ precipitates are developed in Al-Mg alloys, the strength of the alloys will be increased and the strain instability observed in Al-Mg alloys will be improved, because $\mathrm{Al}_{3} \mathrm{Sc}$ precipitates provide a source of Orowan strengthening and homogenize the stress-strain behavior during deformation.

2: If fine $\mathrm{Al}_{3} \mathrm{Sc}$ precipitates are developed in $\mathrm{Al}-\mathrm{Mg}$ alloys, the effect of sensitization and intergranular corrosion observed in $\mathrm{Al}-\mathrm{Mg}$ alloys will be reduced, because $\mathrm{Al}_{3} \mathrm{Sc}$ precipitates help maintain a finer grain structure that is less susceptible to formation of continuous $\mathrm{Al}_{3} \mathrm{Mg}_{2}$ along grain boundaries. 


\section{Experimental}

\subsection{Casting}

A total of 6 alloys were cast at Michigan Technological University's foundry. A $30 \mathrm{~kW}$, $208 \mathrm{~V}, 3$-phase power resistance furnace was used to heat the charge material contained in a glazed alumina crucible. Master alloys for each added alloying element are outlined in Table 1.

Table 1. Composition table of master alloys used during casting.

\begin{tabular}{|ccccccccccc|}
\hline \multicolumn{7}{|c|}{ Alloy Composition $(w t \%)$} \\
\hline Master Alloy & Mg & Fe & Si & Mn & Ti & B & Sc & Zr & Al \\
\hline 1005 & - & 0.04 & 0.02 & - & - & - & - & - & 99.94 \\
Al-Mg & 50 & - & - & - & - & - & - & - & 50 \\
Al-Mn & - & - & - & 25 & - & - & - & - & 75 \\
Tibor & - & - & - & - & 5 & 1 & - & - & 94 \\
Al-Sc & - & - & - & - & - & - & 2 & - & 98 \\
Al-Zr & - & - & - & - & - & - & -5 & 95 \\
\hline
\end{tabular}

The goal for casting was to cast 3 alloys with varying $\mathrm{Mg}$ contents without $\mathrm{Sc}$ and $\mathrm{Zr}$, and then to replicate those 3 alloys with additions of Sc and Zr. Target compositions for each alloy are outlined in Table 2 . 
Table 2. Target chemistries for the 6 cast alloys

\begin{tabular}{|cccccccccccc|}
\hline \multicolumn{10}{|c|}{ Target Composition (wt\%) } \\
\hline \multirow{2}{*}{ Alloy } & $\mathrm{Mg}$ & $\mathrm{Fe}$ & $\mathrm{Si}$ & $\mathrm{Mn}$ & $\mathrm{Ti}$ & $\mathrm{B}$ & $\mathrm{Sc}$ & $\mathrm{Zr}$ & $\mathrm{Al}$ \\
\hline 1 & $\mathrm{Al}-1 \mathrm{Mg}$ & 1.00 & 0.20 & 0.10 & 0.20 & 0.01 & 0.002 & 0.00 & 0.00 & $\mathrm{Rem}$ \\
2 & $\mathrm{Al}-1 \mathrm{Mg}+(\mathrm{Sc}, \mathrm{Zr})$ & 1.00 & 0.20 & 0.10 & 0.20 & 0.01 & 0.002 & 0.08 & 0.16 & $\mathrm{Rem}$ \\
3 & $\mathrm{Al}-3 \mathrm{Mg}$ & 3.00 & 0.20 & 0.10 & 0.20 & 0.01 & 0.002 & 0.00 & 0.00 & $\mathrm{Rem}$ \\
4 & $\mathrm{Al}-3 \mathrm{Mg}+(\mathrm{Sc}, \mathrm{Zr})$ & 3.00 & 0.20 & 0.10 & 0.20 & 0.01 & 0.002 & 0.08 & 0.16 & $\mathrm{Rem}$ \\
5 & $\mathrm{Al}-5 \mathrm{Mg}$ & 5.00 & 0.20 & 0.10 & 0.20 & 0.01 & 0.002 & 0.00 & 0.00 & $\mathrm{Rem}$ \\
6 & $\mathrm{Al}-5 \mathrm{Mg}+(\mathrm{Sc}, \mathrm{Zr})$ & 5.00 & 0.20 & 0.10 & 0.20 & 0.01 & 0.002 & 0.08 & 0.16 & $\mathrm{Rem}$ \\
\hline
\end{tabular}

In order to monitor compositions of alloys during and after casting, small circular "buttons" of material were periodically cast, quenched, and faced to a smooth finish for analysis via optical emission spectroscopy (OES). These "buttons" were cast after additions of the $\mathrm{Zr}$ master alloy, the subsequent additions of the $\mathrm{Mg}, \mathrm{Mn}$, and TiB master alloys, after the subsequent addition of the Sc master alloy, and finally just before final casting. This order was selected to avoid OES interactions between $\mathrm{Zr}$ and Sc additions. Any variation from target chemistries was corrected by further master alloy additions, and subsequent OES measurements before further alloying additions.

Once final chemistries were confirmed, each heat was finally cast into cylindrical billets. A graphite permanent mold measuring 3.5" in diameter and 10 inches in height were used. The bottom of the mold was left open, and the mold was placed into a 1.5 " thick copper chill plate that was machined to have a circular slot for the mold to fit into. This chill plate was then placed onto a pair of aluminum chill plates with copper tubing through which cooling water flowed. Additionally, water-cooled copper tubing was wrapped around the graphite mold. An annotated photo of the casting set-up is shown in Figure 66. 


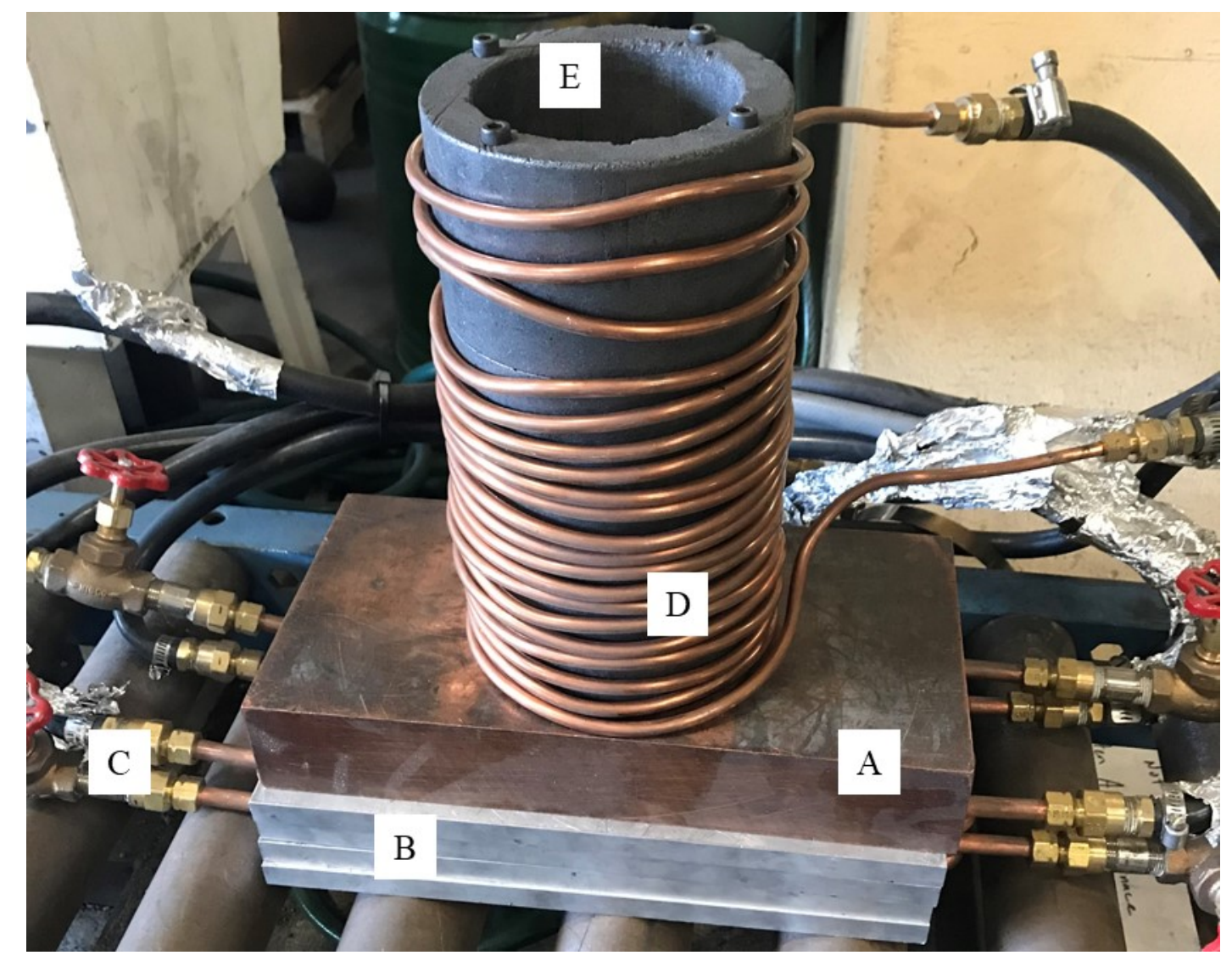

Figure 6. Water-cooled mold with A: Copper chill plate. B: Water cooled aluminum chill plates. C: Water inlet for cooling system. D: Water-cooled copper tubing. E: Graphite permanent mold.

The purpose of the chill plate set-up was to increase cooling rates in order to avoid formation of primary $\mathrm{Al}_{3}\{\mathrm{Sc}, \mathrm{Zr}\}$ precipitates. This method was also used for the alloys not containing Sc and $\mathrm{Zr}$ for consistency. Once the billets were cast and fully solidified, they were removed from the mold and water quenched. Two billets were cast for each alloy, in order to have sufficient material for heat treatment, microscopy and extrusion.

\subsection{Heat Treatment}

Isochronal heat treatment of each of the Sc-containing alloys was conducted in order to evaluate precipitation behavior of the $\mathrm{Al}_{3} \mathrm{Sc}$ and $\mathrm{Al}_{3} \mathrm{Zr}$ secondary phases. Isochronal heat treatment dictates that samples are held for identical timeframes at increasing temperatures. For this testing, sections were taken from the bottom billets of each cast alloy, polished to a 320-grit finish, using silicon carbide polishing wheels, on one side for testing, and polished until flat on the opposite side using coarse silicon carbide polishing wheels. Each cylindrical slice was cut into 4 sections for the heat treatment. Simple box furnaces with internal thermocouples were used for all heat treatment studies. For each heat treatment study, at each step a thermocouple was placed under a sample in the heat treatment oven to monitor the sample temperature. The timing of each step began once 
the parts achieved the desired heat treatment temperature. Subsequent hardness and conductivity measurements were then taken.

Temperatures analyzed for isochronal heat treatment ranged from $150-500{ }^{\circ} \mathrm{C}$ in $25{ }^{\circ} \mathrm{C}$ intervals (excluding $175^{\circ} \mathrm{C}$ and $225^{\circ} \mathrm{C}$ ), and a time step of 3 hours was used for each temperature. Additionally, isothermal heat treatment of each of the $3 \mathrm{Sc}$-containing alloys was conducted in order to evaluate when peak hardening is achieved in each alloy. A temperature of $300{ }^{\circ} \mathrm{C}$ was selected, and times of $2,4,6,8,12,16,20$, and 24 hours were selected for subsequent hardness measurements.

\subsection{Hardness and Conductivity Testing}

Hardness of heat-treated samples was measured using the Rockwell F-scale (60 kgf load, $1 / 16^{\text {th }}$ inch ball indenter). A minimum of 5 data points were taken for each measurement in order to quantify measurement variation and uncertainty. Data was then recorded and plotted to analyze hardening trends in each alloy.

Conductivity measurements were conducted using a Fischer Sigma Scope SMP10 eddy current testing device, using an ES40 probe and $60 \mathrm{kHz}$ frequency. The testing apparatus was placed in a temperature-controlled room, and samples were placed in the testing room for a minimum of 15 minutes before testing to avoid temperature effects on conductivity measurements. A minimum of 10 conductivity measurements were made for each data point to assess uncertainty.

\subsection{Extrusion and Cold Rolling}

In order to perform wrought tensile and corrosion testing, one billet of each of the 6 cast alloys was extruded into plate material. The $3 \mathrm{Sc}$-containing alloys underwent a 2-stage heat treatment prior to extrusion, consisting of 12 hours at $300^{\circ} \mathrm{C}$ to precipitate $\mathrm{Al}_{3} \mathrm{Sc}$ particles, followed by 16 hours at $400{ }^{\circ} \mathrm{C}$ to form the $\mathrm{Al}_{3} \mathrm{Zr}$ phase described in section 2.1.4. The 3 alloys not containing Sc underwent a homogenization heat treatment of 520 ${ }^{\circ} \mathrm{C}$ for 5 hours prior to extrusion. The skin of each billet was then removed by turning 1.5 $\mathrm{mm}$ from the diameter.

A 550-ton extrusion press with a 3.5-inch container diameter was used for extruding the cast billets. A $4 \mathrm{~mm}$ x $60 \mathrm{~mm}$ steel extrusion die was used for the plate extrusion, resulting in an extrusion ratio of roughly $25: 1$. Prior to extrusion, each billet was preheated to $450{ }^{\circ} \mathrm{C}$, and the extrusion die and container were preheated to $425^{\circ} \mathrm{C}$. Approximately $15 \%$ of the length of each billet was left unextruded. The extruded material was then allowed to air cool. The leading 18 inches of each extrusion were scrapped to ensure steady state extrusion properties.

The extruded material was cold rolled for the subsequent tensile and corrosion testing. For all such material, a reduction in thickness of $50 \%$ (nominally) to $2 \mathrm{~mm}$ was targeted. Cold rolling was conducted in increments of $.25 \mathrm{~mm}$ per pass until final thickness was achieved. After cold rolling, all rolled material was stretched a nominal $1.5 \%$ of length, 
purely for the purpose of straightening the material from any bends and curves produced while rolling.

\subsection{Mechanical Testing}

The ASTM standard E8/E8M-16a was used for tensile testing, notably in defining dimensions of the fabricated test samples. A 10,000 $\mathrm{lb}$ load cell and 1-inch wide tensile grips were used for all tensile testing. A 2-inch Epsilon Technology extensometer was used to measure strain during testing. To control and analyze the tests, MTS TestSuite TW elite software version 4.4.1.525 was used.

\subsubsection{Sample Preparation}

Per the aforementioned ASTM standard, tensile "dog bones" were machined from the extruded and rolled plate prepared for tensile testing for each of the 6 extruded alloys detailed in section 3.3. Each alloy was flash annealed at $350{ }^{\circ} \mathrm{C}$ prior to machining. Enough specimens were fabricated to allow for a minimum of 6 specimens for each alloy, 3 for each designated strain rate within that alloy. The "sheet-type" flat specimen dimensions specified in the standard were used; specimens were machined to have a 50 $\mathrm{mm}$ gauge length, $12.5 \mathrm{~mm}$ gauge width, $57 \mathrm{~mm}$ reduced gauge section, $50 \mathrm{~mm}$ long grips, and a $12.5 \mathrm{~mm}$ fillet radius. The resulting cross section within the gauge section was $12.5 \mathrm{~mm} x$ part thickness. The gauge width of each specimen was measured using digital calipers to $\pm 0.01 \mathrm{~mm}$, and the thickness of each was measured using digital micrometers to $\pm 0.001 \mathrm{~mm}$, and this information was recorded.

\subsubsection{Strain Rate Variation}

In order to capture different PLC effect behaviors two sets of tests were performed for each alloy at two different strain rates. Strain rates of $10^{-3}$ and $10^{-4} \mathrm{~s}^{-1}$ were used for these two sets. The MTS tensile software used had the capacity to measure and maintain strain rate during testing, so strain rates were specified within the software for each test.

\subsection{Corrosion Testing}

Of particular interest in corrosion testing Al-Mg alloys is intergranular corrosion, as mentioned in section 1.2. A standard test for intergranular corrosion is ASTM Standard G67-13. This is a nitric acid mass loss test (NAMLT) used specifically for 5xxx series aluminum alloys. All corrosion testing was conducted in accordance with this standard, with the deviation that the temperature control of the test reagent was accurate to $\pm 1.0^{\circ} \mathrm{C}$ rather than $\pm 0.1{ }^{\circ} \mathrm{C}$ as called out in the standard. Additionally, the concentrated $\mathrm{HNO}_{3}$ was ACS grade $68-70 \%$ pure, slightly different than the $70-72 \%$ pure $\mathrm{HNO}_{3}$ called out in the standard. Water used for rinsing was in compliance with the specified DI water called out in the standard. 


\subsubsection{Sample Preparation}

Corrosion samples were fabricated from the 6 alloys after extrusion and rolling as detailed in Section 3.4. Four sample conditions were tested of each alloy, outlined in Table 3.

Table 3. Heat treatments conducted after rolling for corrosion samples.

\begin{tabular}{|cc|}
\hline Condition & Heat Treatment \\
\hline 1 & None \\
2 & $150 \mathrm{C}, 24$ Hours \\
3 & $250 \mathrm{C}, 1$ Hour \\
4 & $250 \mathrm{C}, 1$ Hour \& $150 \mathrm{C}, 24$ Hours \\
\hline
\end{tabular}

Three coupons of each sample were fabricated on a CNC mill per ASTM standard G6713 , with dimensions of $50 \mathrm{~mm} \times 6 \mathrm{~mm} \times$ thickness.

After samples were machined, the edges of each sample were smoothed using fine emery paper. For each coupon, exact length and width dimensions were measured using digital calipers accurate to $0.01 \mathrm{~mm}$, and thickness was measured using a digital micrometer accurate to $0.001 \mathrm{~mm}$. Each coupon was soaked for one minute in a $5 \% \mathrm{NaOH}$ solution held at $80{ }^{\circ} \mathrm{C}$, water rinsed, and then soaked for 30 seconds in concentrated $\mathrm{HNO}_{3}$ and water rinsed, all in compliance with the aforementioned ASTM standard. The mass of each sample was then measured to $\pm 1.0 \mathrm{mg}$.

\subsubsection{Test Set-Up}

A 10 " x 10 " plywood sheet was machined to contain a grid of 36 holes to accommodate $75 \mathrm{~mL}$ glass test tubes with a $25 \mathrm{~mm}$ outer diameter. Additionally, four 6" steel bolts were attached to the corners of the grid to form a stand. This stand was placed in a large steel tub with of sufficient size to fill with water up to a level of 1 " below the bottom of the plywood grid. The steel tub was placed on a small hot plate, filled with water to the appropriate level, and the plywood test stand was placed within. The hot plate was plugged into a temperature control unit that used a thermocouple to monitor the temperature of the water and cycle power to the hot plate to maintain the water at $30^{\circ} \mathrm{C}$. Thirty-six of the aforementioned $75 \mathrm{~mL}$ glass test tubes were placed in the holes in the plywood grid for the test.

The ASTM standard calls for a minimum reagent volume to specimen surface area ratio of $30 \mathrm{~L} / \mathrm{in}^{2}$. For this test, $50 \mathrm{~mL}$ of concentrated $\mathrm{HNO}_{3}$ reagent was placed in each test tube, and each test tube contained a single coupon. The resulting reagent volume to surface area ratio was about $60 \mathrm{~mL} / \mathrm{in}^{2}$ for each sample. 


\subsubsection{NAMLT Testing}

After filling each test tube with $50 \mathrm{~mL}$ of concentrated $\mathrm{HNO}_{3}$, one coupon was placed in each test tube, and the identity of each sample was tracked by marking the location on the test grid. Once each of the 36 test tubes contained a sample, a sheet of aluminum foil was wrapped over top of the test tubes to act as a loose-fitting cover during the test. The samples were then held in the temperature-controlled test environment for 24 hours, and were then removed, water rinsed, and set aside for further measurements. This was then repeated for the second set of 36 test coupons.

Each test coupon was thoroughly scrubbed using a stiff plastic bristle brush while rinsing with DI water to remove any adhering particles and corrosion products and allowed to air dry. Once dry, the mass of each sample was again measured to $\pm 1.0 \mathrm{mg}$ and recorded. Only four samples required additional product removal in accordance with ASTM Practice G1, namely the Al-5 wt $\% \mathrm{Mg}$ and Al-5 wt $\% \mathrm{Mg}$-Sc alloys in the rolled + sensitized and the rolled + stabilized + sensitized conditions. For these alloys, only one additional round of brushing was necessary to obtain a constant mass.

Once the masses of each test coupon after corrosion were recorded, corrosion rate in terms of $\mathrm{mg} / \mathrm{cm}^{2}$ was calculated for each coupon, and average and standard deviation values were calculated for each sample.

\subsection{Microscopy}

For analysis of grain structure, corrosion effects, sensitization, etc. of tensile and corrosion testing specimens, scanning electron microscopy (SEM) and optical microscopy were used. Only secondary and back-scattered electron analyses were utilized in SEM work. In order to analyze samples they were metallographically prepared as follows.

\subsubsection{Metallographic preparation}

All samples that were analyzed using SEM were mounted in 1.25-inch diameter round molds using EpoxySet resin (Allied High Tech Products, Rancho Dominguez, CA) such that the viewing direction was normal to the extrusion and rolling direction. For the corrosion samples that were analyzed, a vacuum impregnation system was used to ensure that the epoxy sufficiently penetrated the corrosion layers to avoid loss of material during polishing as well as air entrapment during resin solidification. Once samples were mounted, they were polished in multiple steps as follows:

Between each polishing step, samples were washed with warm water, soap, and cotton, and then rinsed with ethanol. Each sample surface was ground to a plane manually using 320 grit $\mathrm{SiC}$ paper and a water wash, for as much time necessary to achieve a planar surface. Each subsequent polishing step was completed using a Struers Labo-Pol three sample autopolisher, following the steps shown in Table 4. 
Table 4. Polishing procedure for metallographic sample preparation.

\begin{tabular}{|ccccc|}
\hline $\begin{array}{c}\text { Polishing } \\
\text { Step }\end{array}$ & Pad & Abrasive & Time & Pressure \\
\hline 1 & Allied SiC Paper & 320 grit SiC & As Required & Manual \\
2 & $\begin{array}{c}\text { Struers MD- } \\
\text { Largo }\end{array}$ & $\begin{array}{c}\text { Allied 15-micron diamond, } \\
\text { glycol suspension }\end{array}$ & $3-5$ minutes & $30 \mathrm{~N}$ \\
3 & Struers MD-Mol & $\begin{array}{c}\text { Allied 3-micron } \\
\text { monocrystalline diamond } \\
\text { paste, Allied RedLube } \\
\text { Allied 0.04-micron silica } \\
\text { suspension }\end{array}$ & $3-5$ minutes & $25 \mathrm{~N}$ \\
4 & Allied Final P & $\begin{array}{c}\text { 2 minutes } \\
\text { Alling }\end{array}$ & $15 \mathrm{~N}$ \\
\hline
\end{tabular}

After polishing, samples were viewed under optical microscope to ensure the polish was acceptable for SEM analysis. Once polished, samples were etched using Keller's reagent for 20-30 seconds to highlight grain boundaries. After the first round of etching, samples were again viewed under optical microscope to ensure grain boundaries were identifiable, and additional etching steps were conducted as necessary.

For SEM analysis of the corrosion samples, an extra step had to be completed to avoid issues with epoxy material impregnated within the corrosion layer. After etching, samples were coated in a carbon layer to aid in SEM analysis.

\subsubsection{Microscope work}

SEM analysis was conducted using an FEI/Phillips XL-40 ESEM at an accelerating voltage of $15 \mathrm{kV}$. As mentioned before, the primary analysis methods used were secondary electron (SE) and back-scattered electron (BSE) techniques. Additionally, some optical microscopy was conducted on samples with fine grain structures. All microscopy images were taken normal to the rolling direction, as depicted in Figure 6.

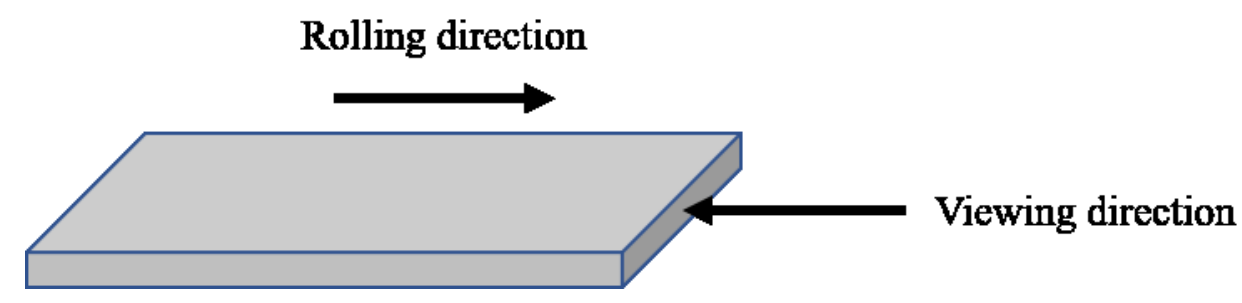

Figure 7. Diagram of microscopy viewing angle relative to rolling direction.

\subsection{TEM}

To observe and analyze $\mathrm{Al}_{3} \mathrm{Sc}$ precipitate formation, TEM analysis was used. Samples from alloys 2, 4, and 6 were heat treated, sectioned, and manual polished at Michigan 
Technological University, and electropolishing and TEM analysis was conducted at Deakin University, Victoria, Australia. Samples of each alloy were made after heat treatments of 12 and 24 hours at $300{ }^{\circ} \mathrm{C}$, making a total of 6 samples for TEM analysis.

\subsubsection{Polishing and Electropolishing}

After heat treatment of all material, samples were cut into sections measuring roughly 15 $\mathrm{mm} \times 15 \mathrm{~mm} \times 140$ microns using a wire EDM cutting machine. These sections were manually polished using 800 grit and 1200 grit $\mathrm{SiC}$ paper until a thickness of nominally 100 microns or less was achieved. Once the proper thickness was achieved, discs measuring $3 \mathrm{~mm}$ in diameter were punched and electropolished.

Once the $3 \mathrm{~mm}$ discs were prepared, they were electropolished to their final condition for TEM analysis. Electropolishing was conducted using a twin-jet Tenupol electropolishing unit with an electrolyte solution of 33\% nitric acid in methanol at an operating voltage of 15 volts and a temperature of $-25^{\circ} \mathrm{C}$. Each foil was electropolished until current through the foil was broken, indicating a hole had been pierced in the material and that the sample was ready for TEM viewing. After electropolishing, many samples are not of sufficient quality to collect useful images or data, so enough foils of each sample were prepared to ensure that the necessary results could be collected.

\subsubsection{Microscope Work}

All TEM images and results presented were conducted on a JEOL FEG 2100F (JEOL Ltd. Japan) instrument at Deakin University (Victoria, Australia). The instrument was operated at a voltage of $200 \mathrm{kV}$. Darkfield analysis was not able to be conducted successfully, so all presented images were completed using brightfield analysis. 



\section{Results}

\subsection{Casting}

A total of 6 different alloys were cast for examination. Achieving and accurately measuring the chemistries of each alloy is a crucial step in the analysis process. As explained in section 3.1, the chemistry of each alloy was monitored and checked during casting using an OES at Michigan Technological University. The 3 alloys containing Sc and $\mathrm{Zr}$ (alloys 2, 4, and 6) were also sent to Lehigh Testing Laboratories in New Castle, Delaware for analysis using inductively coupled plasma (ICP) mass spectrometry to provide secondary analysis. The measured chemistries of each alloy, using both methods, are provided in Table 5. 
Table 5. Measured chemistries of the 6 alloys cast at Michigan Technological University. Results from both OES and ICP analyses are provided.

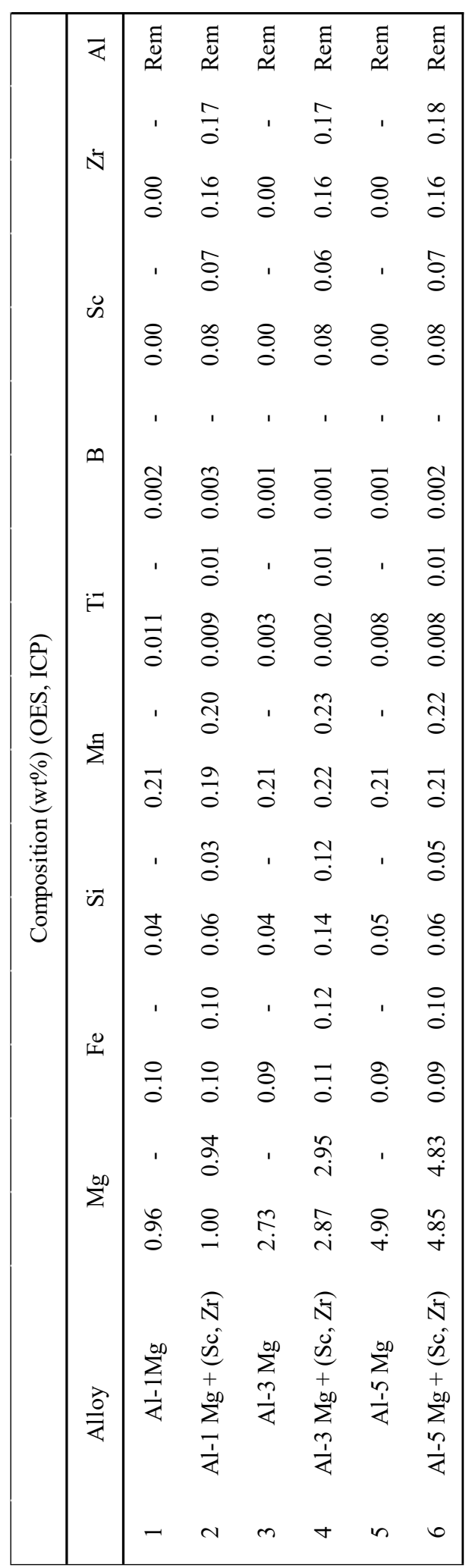




\subsection{Processing Microscopy}

In order to understand the grain structure in the 6 alloys after the severe mechanical processing conditions involved with extrusion and rolling, microscopy was conducted on each alloy, viewed as outlined in Figure 7. Samples of fully prepared tensile specimens (including the flash anneal) were taken for each alloy, polished according to section 3.7.1, and chemically etched. Chemical etching involved a pre-etch of $\mathrm{NaCl}$ in $\mathrm{H}_{3} \mathrm{PO}_{4}$ followed by submersion in Weck's reagent as outlined in [18]. Images of grain structure for each alloy are presented in Figure 8.

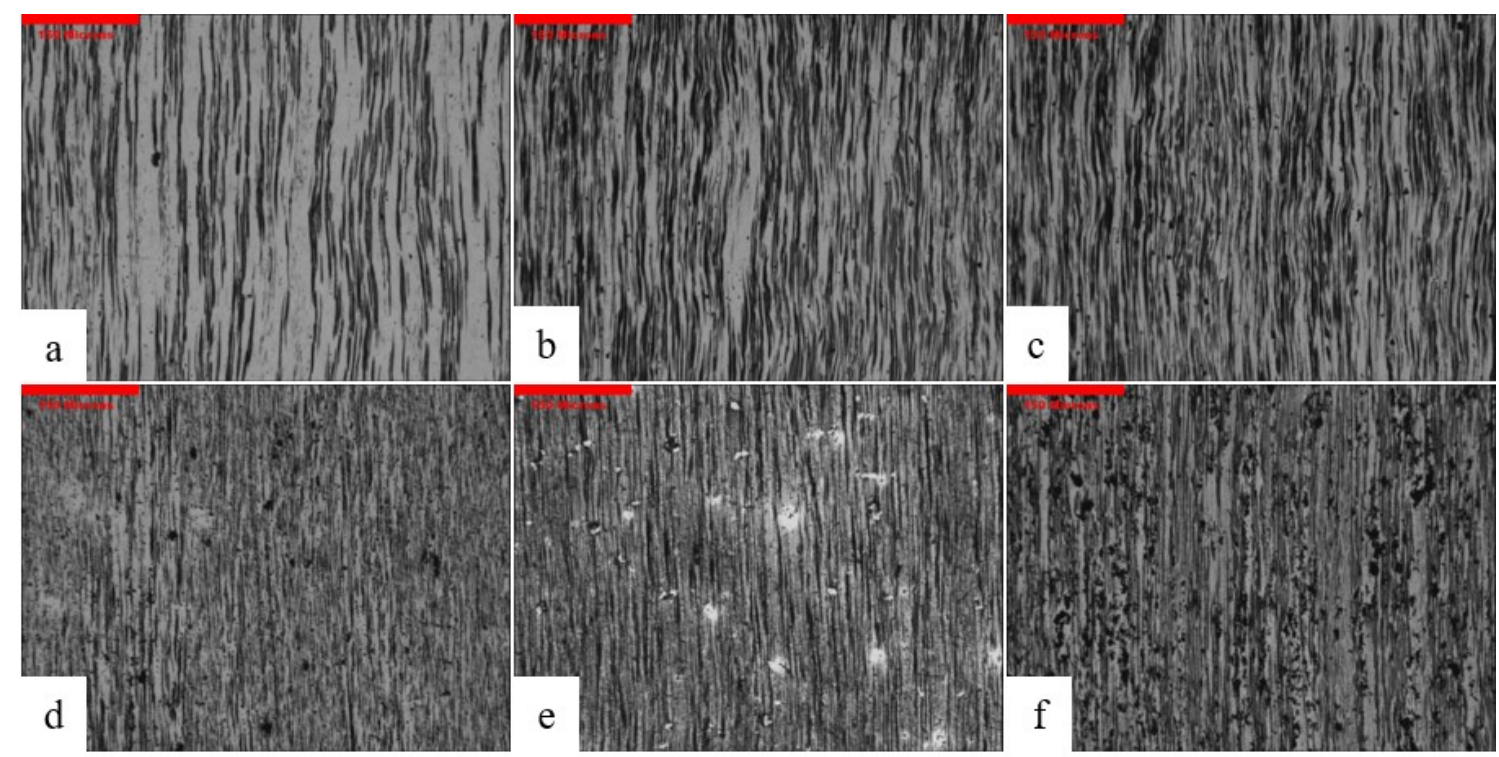

Figure 8. Optical microscopy images of prepared tensile samples. Scale bars shown in red are 150 microns. Right and left of each image represent top and bottom of thickness direction. Shown in order: a) Alloy 1, b) Alloy 3, c) Alloy 5, d) Alloy 2, e) Alloy 4, f) Alloy 6.

Using line intersection of grain boundaries, an estimate of grain size was then calculated for each alloy. Given the severe grain orientation, these data should be taken as a qualitative measurement of changes in grain size, rather than accurate quantitative measurements. The grain size measurements for each alloy are presented in Table 6. 
Table 6. Results of grain size analysis for as prepared tensile samples. Uncertainty is given by $95 \%$ confidence interval

\begin{tabular}{|cccc|}
\hline Alloy & \multicolumn{3}{c|}{ Grain Size, $\mu \mathrm{m}^{2}$} \\
\hline 1 & 7.4 & \pm & 0.7 \\
2 & 5.3 & \pm & 0.4 \\
3 & 5.2 & \pm & 0.2 \\
4 & 4.5 & \pm & 0.1 \\
5 & 5.1 & \pm & 0.2 \\
6 & 4.8 & \pm & 0.1 \\
\hline
\end{tabular}

Although these numbers are not accurate grain size calculations, there is a trend in reduction of grain size due to the presence of $\mathrm{Al}_{3} \mathrm{Sc}$ observed, which is also seen when comparing these alloys in the optical micrographs shown in Figure 8.

\subsection{Heat Treatment}

Two separate heat treatments were conducted in order to evaluate the development of properties in the 3 cast alloys containing Sc and $\mathrm{Zr}$. An initial isochronal heat treatment was conducted in order to determine temperatures at which the nucleation of the $\mathrm{Al}_{3} \mathrm{Sc}$ and $\mathrm{Al}_{3} \mathrm{Zr}$ occurred, and hardness and conductivity were tracked for each as a measure of this study. The hardness and conductivity results of the isochronal heat treatment for the precipitate containing alloys are shown in Figures 9 and 10, respectively.

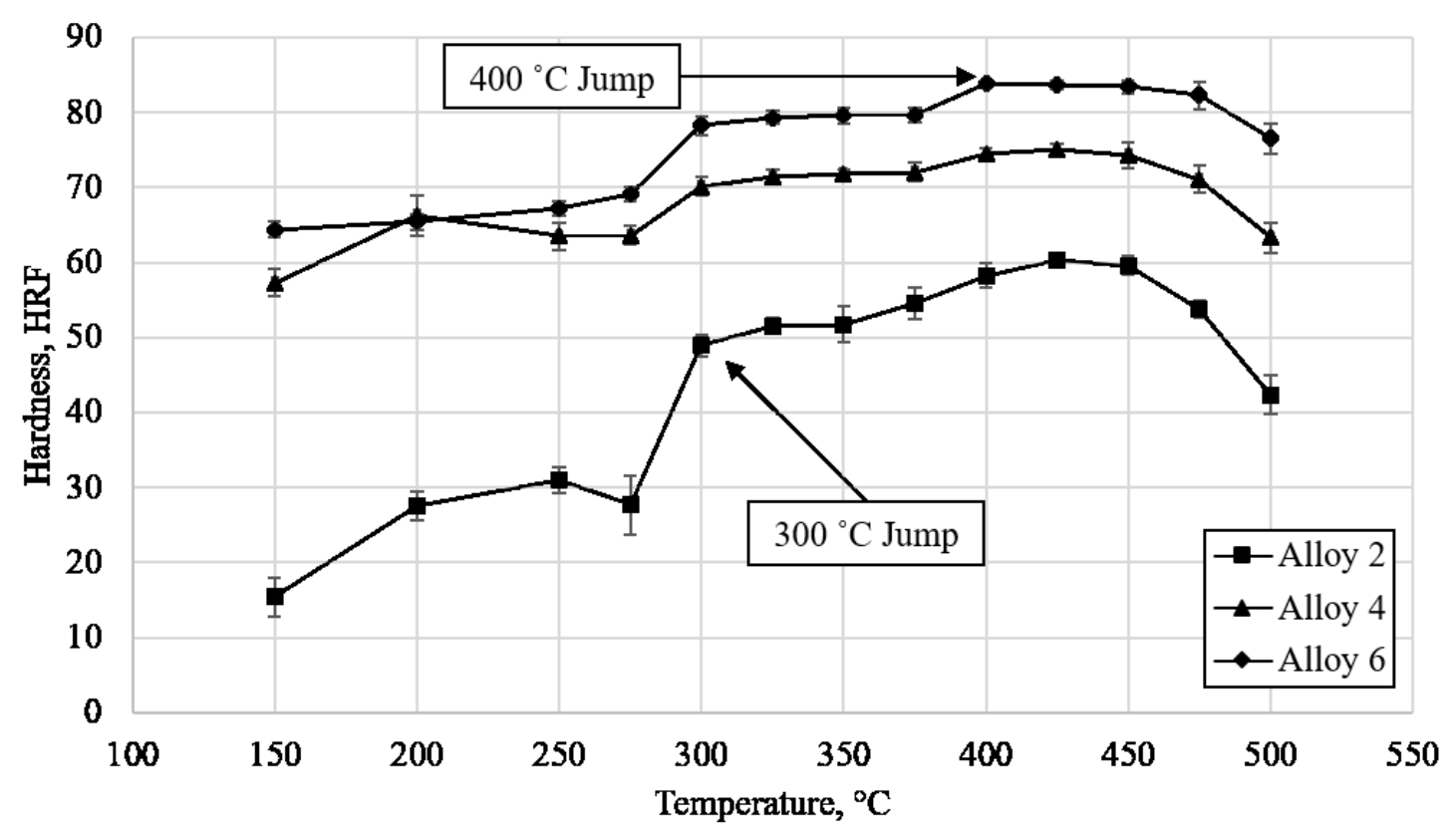

Figure 9. Rockwell hardness results from isochronal heat treatment of alloys 2, 4, and 6. HRF scale is shown. Error bars show standard deviations of each measurement. Notable increases at $300{ }^{\circ} \mathrm{C}$ and $400{ }^{\circ} \mathrm{C}$ marked 


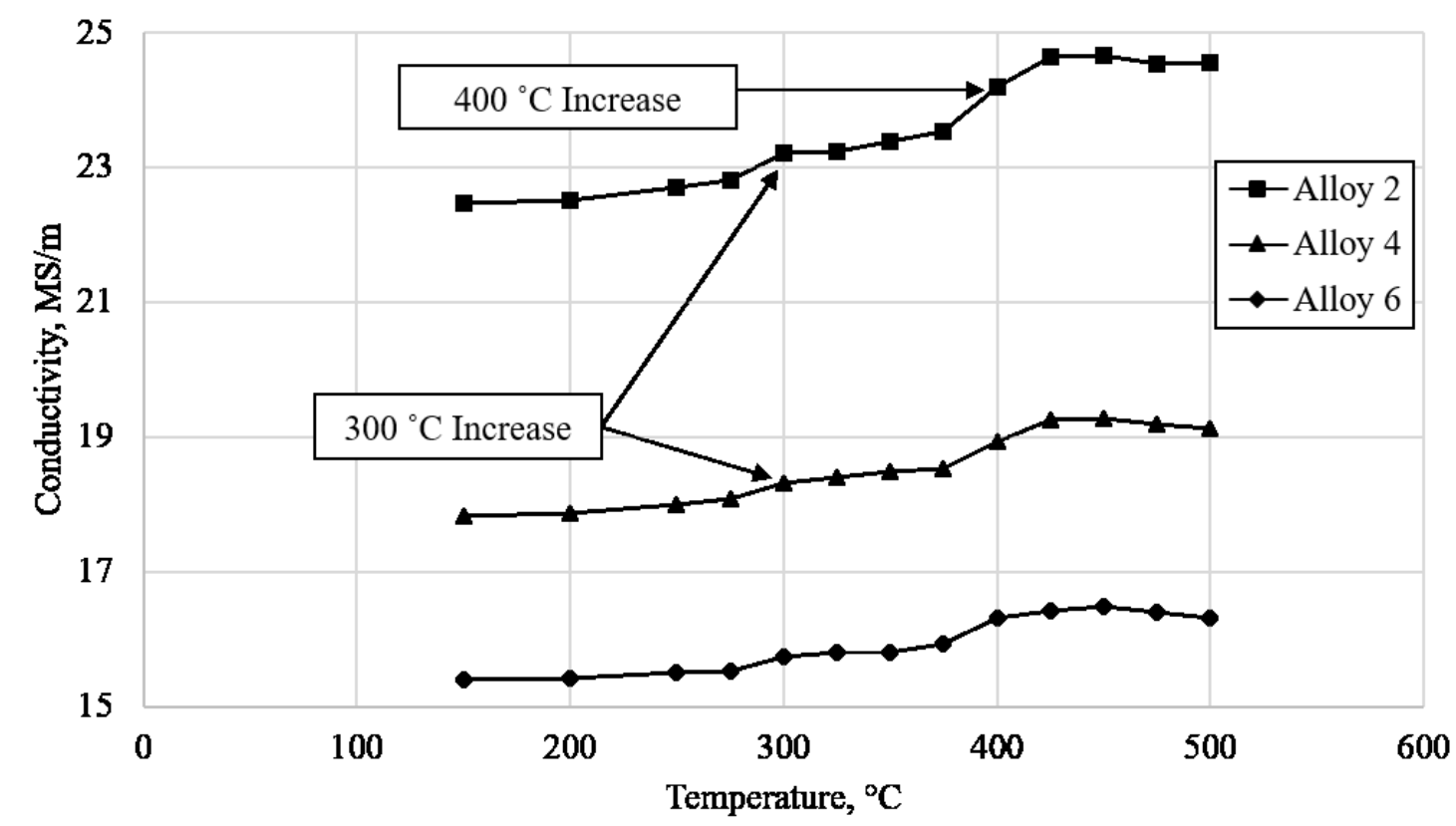

Figure 10. Eddy current conductivity results from isochronal heat treatment of alloys 2, 4, and 6. Increases at $300{ }^{\circ} \mathrm{C}$ and $400{ }^{\circ} \mathrm{C}$ marked.

From the isochronal results, it was observed that there was a large increase in hardness after the alloys had undergone the $300{ }^{\circ} \mathrm{C}$ heat treatment step, and another large increase at the $400{ }^{\circ} \mathrm{C}$ step. These also correlate to sudden increases in conductivity in each alloy, which are indicators of increased solute coming out of solution. Given this data, these were taken to be the temperatures at which considerable nucleation and growth of the $\mathrm{Al}_{3} \mathrm{Sc}$ and $\mathrm{Al}_{3} \mathrm{Zr}$ precipitates, respectively, had occurred. Therefore, these temperatures were used for the isothermal heat treatment of the alloys prior to the extrusion and rolling was completed. To further understand the development of the $\mathrm{Al}_{3} \mathrm{Sc}$ precipitates, isothermal heat treatment at $300{ }^{\circ} \mathrm{C}$ was also conducted for alloys 2,4 , and 6 , focusing on the hardness development of the alloys. The hardness results for the three alloys are shown in Figure 1111, 12, and 13. 


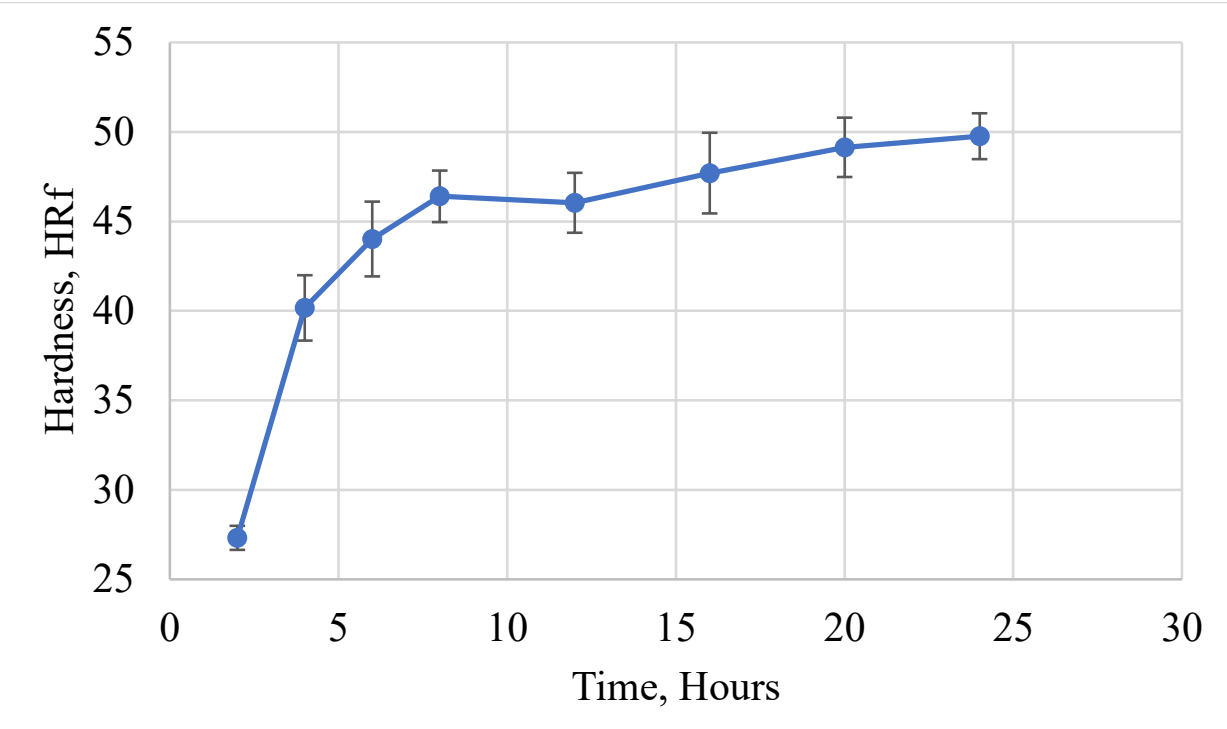

Figure 11. Hardness results of isothermal heat treatment of alloy 2 at $300{ }^{\circ} \mathrm{C}$

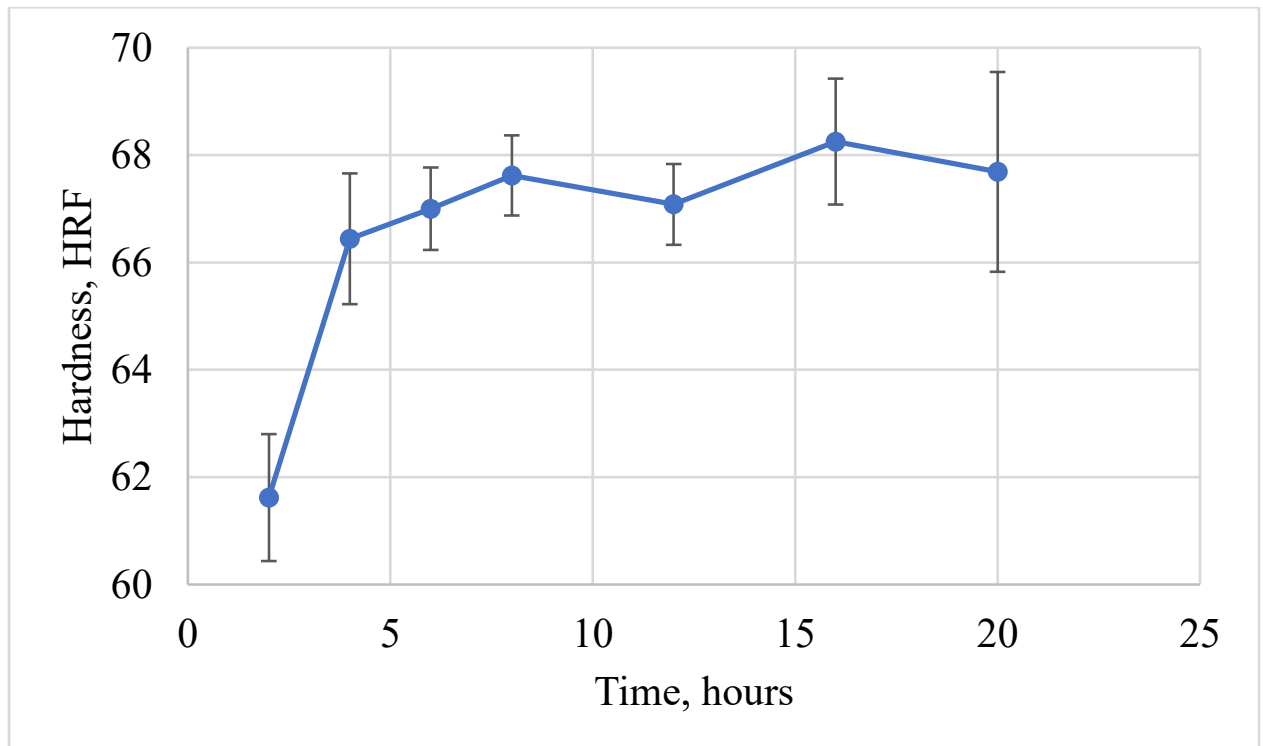

Figure 12. Hardness results of isothermal heat treatment of alloy 4 at $300{ }^{\circ} \mathrm{C}$ 


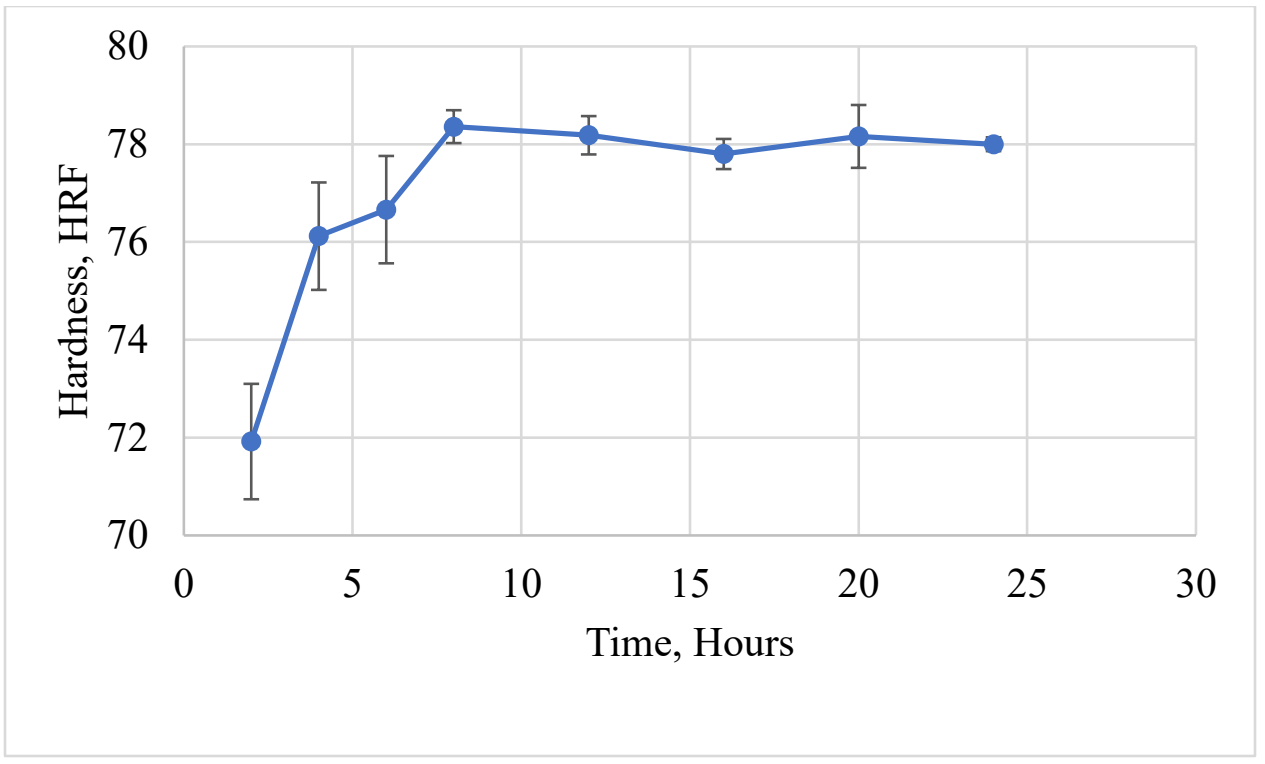

Figure 13. Hardness results of isothermal heat treatment of alloy 6 at $300{ }^{\circ} \mathrm{C}$

All three of these alloys showed very similar hardening trends, with an initial peak hardness occurring after 8 hours, and a general plateau in hardness thereafter, suggesting that the kinetics of nucleation and growth are consistent between the alloys. This data was used to determine the specific heat treatment to be conducted on the material that was extruded and used for further testing. Namely, that 12 hours at $300{ }^{\circ} \mathrm{C}$ would be sufficient to produce peak hardening from $\mathrm{Al}_{3} \mathrm{Sc}$ precipitation in all three alloys, which is optimal for use in further testing, as unnecessary heat treatment is desirable to be avoided. However, this peak strength is below the values obtained during isochronal heat treatment

\subsection{Mechanical Testing}

From the tensile testing results, there were generally two areas of interest. The first is in mechanical performance, i.e. yield strength, tensile strength, elongation, and elastic modulus. The second is the behavior associated with non-homogenous strain and the PLC effect, discussed in section 2.2. The development of the $\mathrm{Al}_{3}\{\mathrm{Sc}, \mathrm{Zr}\}$ precipitates contributed precipitate strengthening to the alloys. The tabulated mechanical properties for each alloy are presented in Table 7. 
Table 7. Average strength and elongation values of alloys 1-6 from tensile testing.

\begin{tabular}{|ccccc|}
\hline Alloy & $\begin{array}{c}\text { Strain Rate, } \\
\mathrm{s}^{-1}\end{array}$ & $\begin{array}{c}\text { Offset Yield } \\
\text { Stress, MPa }\end{array}$ & $\begin{array}{c}\text { Ultimate Stress, } \\
\mathrm{MPa}\end{array}$ & $\begin{array}{c}\text { Strain, } \\
\mathrm{mm} / \mathrm{mm}\end{array}$ \\
\hline \multirow{2}{*}{1} & $10^{-3}$ & 102.5 & 126.9 & 0.11 \\
& $10^{-4}$ & 102.1 & 128.1 & 0.08 \\
2 & $10^{-3}$ & 179.1 & 218.2 & 0.08 \\
& $10^{-4}$ & 181.2 & 219.6 & 0.07 \\
3 & $10^{-3}$ & 104.5 & 221.7 & 0.25 \\
& $10^{-4}$ & 107.1 & 226.7 & 0.24 \\
4 & $10^{-3}$ & 225.2 & 301.0 & 0.09 \\
& $10^{-4}$ & 222.0 & 303.1 & 0.09 \\
5 & $10^{-3}$ & 136.0 & 281.8 & 0.25 \\
& $10^{-4}$ & 137.2 & 289.6 & 0.25 \\
6 & $10^{-3}$ & 261.6 & 361.6 & 0.10 \\
& $10^{-4}$ & 263.0 & 370.8 & 0.10 \\
\hline
\end{tabular}

It is evident that for a given $\mathrm{Mg}$ content, the development of $\mathrm{Al}_{3}\{\mathrm{Sc}, \mathrm{Zr}\}$ precipitates led to significant increases in the yield and ultimate strengths of the alloys, while simultaneously decreasing the strain at failure. Moreover, the improvement increment for yield strength was consistently greater than that for the ultimate strength in each alloy pair. Of additional note is the lack of ductility in alloy 1, which had the lowest $\mathrm{Mg}$ content and no precipitate additions, compared to the other Sc-free alloys, 3 and 5. In order to understand the cause of this, metallography is required to understand grain size and recrystallization effects.

As discussed in section 3.6.2, for tensile testing of the 6 alloys, two different strain rates were used in order to analyze the different behaviors of the PLC effect. This was done in an effort to analyze multiple PLC behavior types in each alloy, and to better describe and analyze the difference in PLC behavior with the development of $\mathrm{Al}_{3}\{\mathrm{Sc}, \mathrm{Zr}\}$ precipitates. Chart overlays comparing each alloy pair at the two different strain rates are shown in Figures 14-19. 


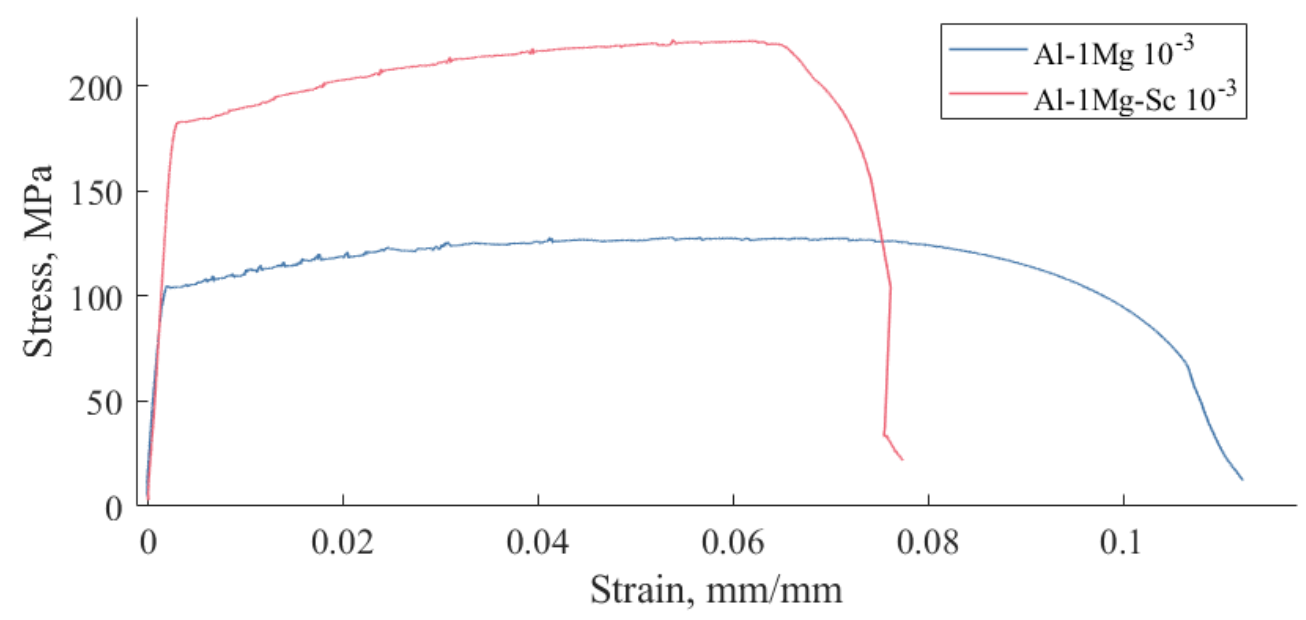

Figure 14. Tensile test results of alloys 1 and 2 at a strain rate of $10^{-3}(\mathrm{~mm} / \mathrm{mm}) / \mathrm{s}$

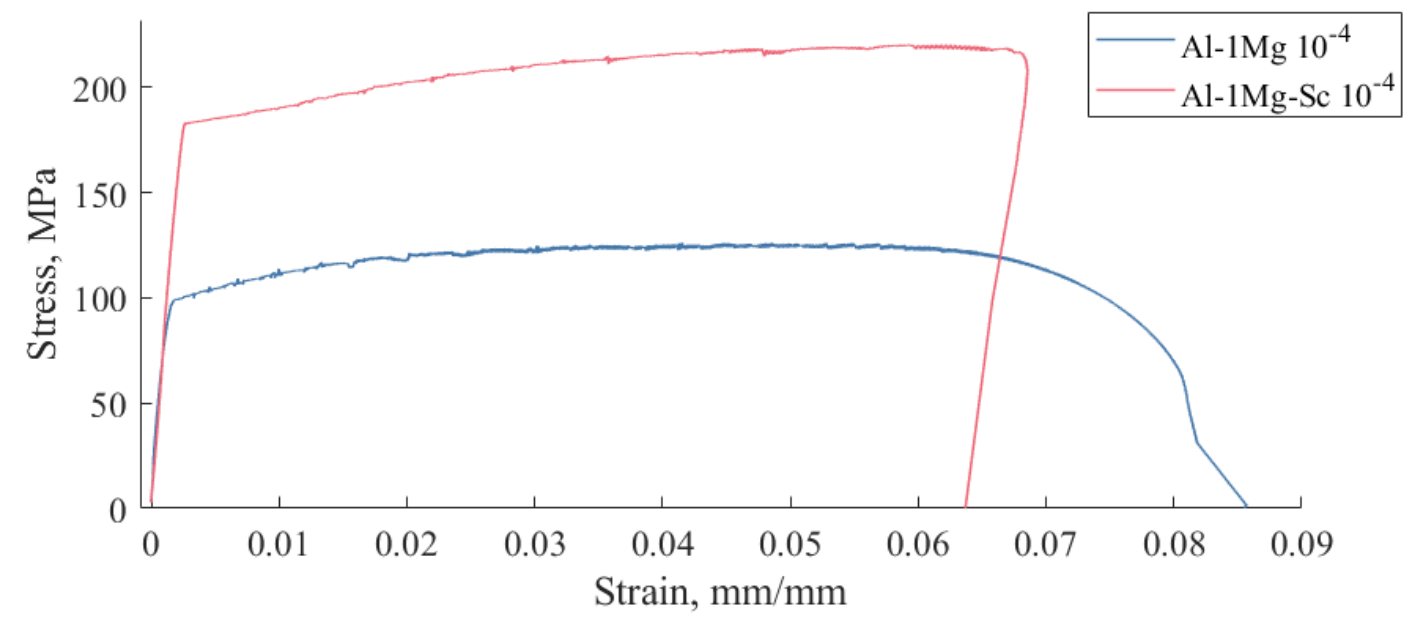

Figure 15. Tensile test results of alloys 1 and 2 at a strain rate of $10^{-4}(\mathrm{~mm} / \mathrm{mm}) / \mathrm{s}$ 


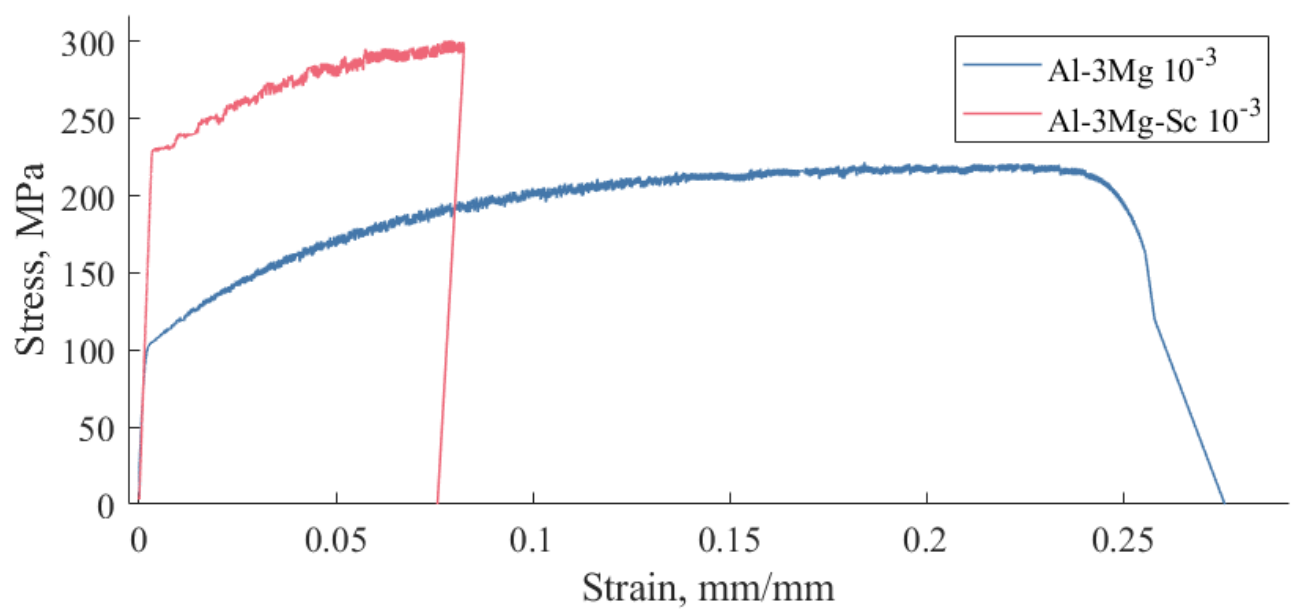

Figure 16. Tensile test results of alloys 3 and 4 at a strain rate of $10^{-3}(\mathrm{~mm} / \mathrm{mm}) / \mathrm{s}$

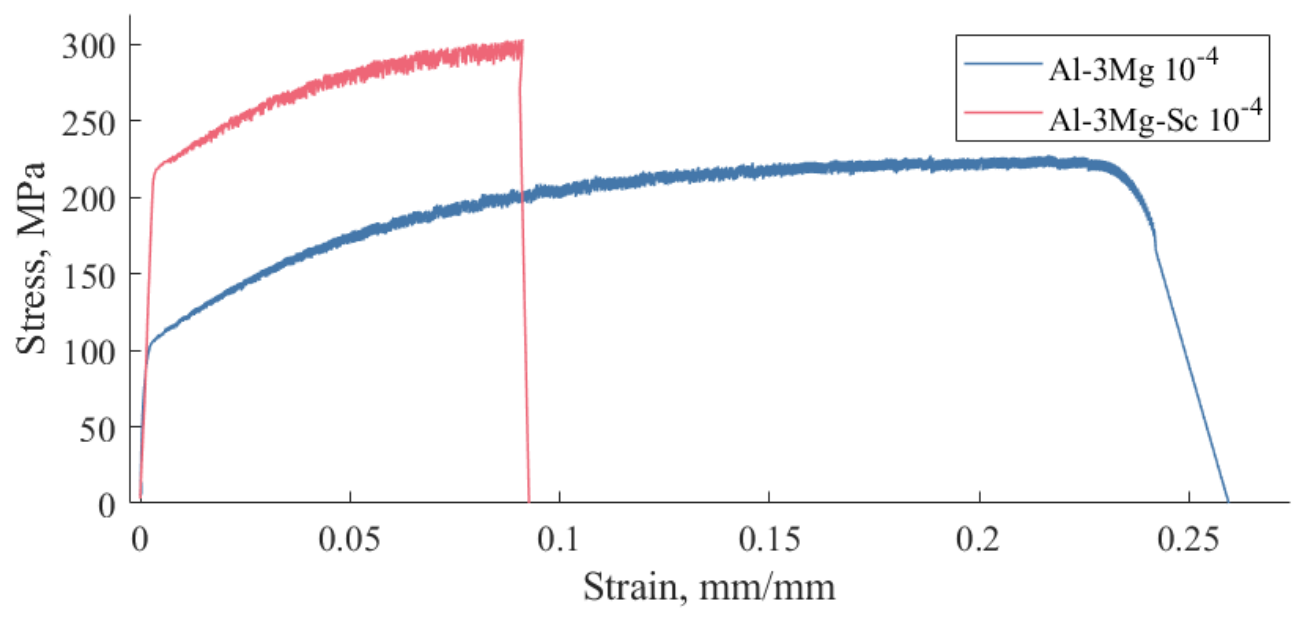

Figure 17. Tensile test results of alloys 3 and 4 at a strain rate of $10^{-4}(\mathrm{~mm} / \mathrm{mm}) / \mathrm{s}$ 


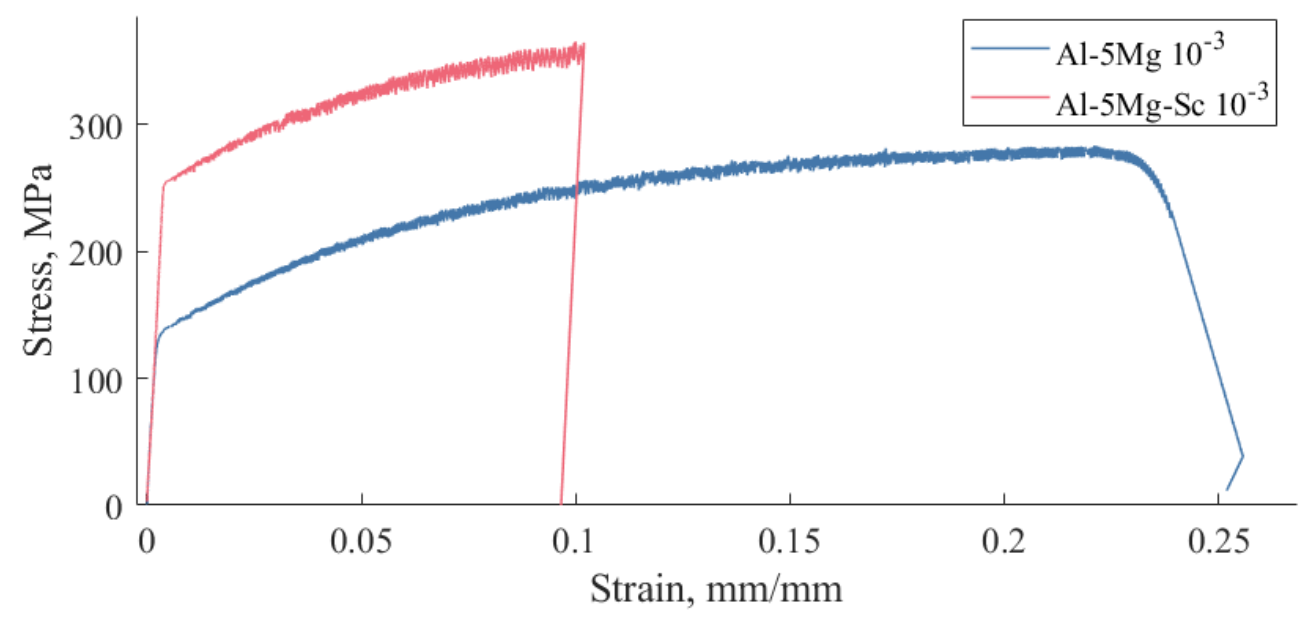

Figure 18. Tensile test results of alloys 5 and 6 at a strain rate of $10^{-3}(\mathrm{~mm} / \mathrm{mm}) / \mathrm{s}$

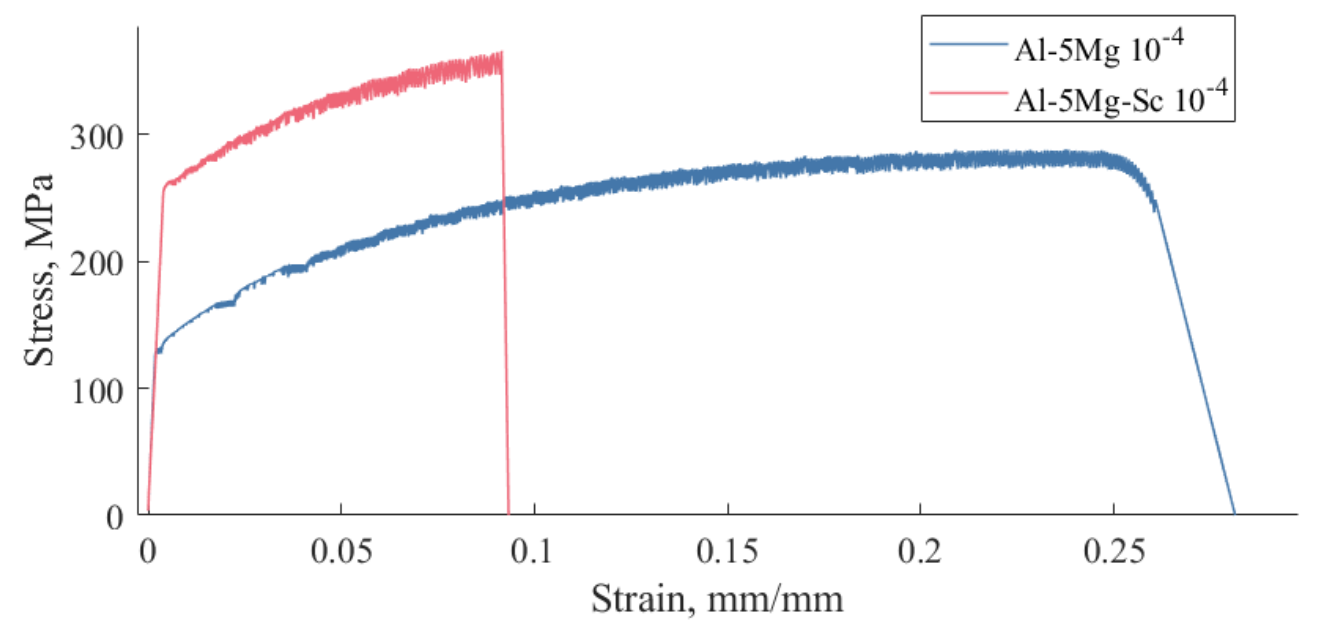

Figure 19. Tensile test results of alloys 5 and 6 at a strain rate of $10^{-4}(\mathrm{~mm} / \mathrm{mm}) / \mathrm{s}$

These charts display the difference in mechanical performance as well as PLC behavior between alloys with and without $\mathrm{Al}_{3}\{\mathrm{Sc}, \mathrm{Zr}\}$ dispersoids, and some of the general trends associated with strain rate sensitivity. A summary of the observed PLC behavior types is given in Table 7. In alloys 1 and 2, which had the lowest Mg content of the 6 cast alloys, at both strain rates the PLC behavior is entirely or nearly entirely Type A in nature. Furthermore, alloy 2 appears to have slightly less severe stress-strain variation compared to alloy 1 , a result of the $\mathrm{Al}_{3}\{\mathrm{Sc}, \mathrm{Zr}\}$ precipitates. This improvement trend changes when comparing the other two alloy pairs. In alloys 3 and 4, at the higher tested strain rate, the Sc-containing alloy does appear to retain more Type A behavior, however the stress variation magnitudes in the dominating Type $\mathrm{B}$ behavior regions are not different between the alloys. At the lower strain rate, both alloys exhibit entirely Type B behavior, and once again the stress variation magnitudes are not improved in the presence of Sc. At a strain rate of $10^{-3} \mathrm{~s}^{-1}$, both alloys 5 and 6 show entirely Type B PLC behavior. However, 
at a strain rate of $10^{-4} \mathrm{~s}^{-1}$, during plastic deformation alloy 5 initially shows some Type C behavior, characterized by infrequent but large stress drops.

Table 8. Summary of observed PLC behavior types in tensile tests for all 6 tested alloys. Results at both tested strain rates are shown.

\begin{tabular}{|ccc|}
\hline Alloy & Strain Rate & Observed PLC Behavior \\
\hline \multirow{2}{*}{1} & $10^{-3}$ & Type A \\
& $10^{-4}$ & Type A \\
2 & $10^{-3}$ & Type A \\
& $10^{-4}$ & Type A \\
3 & $10^{-3}$ & Type A \& Type B \\
& $10^{-4}$ & Type B \\
4 & $10^{-3}$ & Type B \\
& $10^{-4}$ & Type B \\
5 & $10^{-3}$ & Type B \\
& $10^{-4}$ & Type B \& Type C \\
6 & $10^{-3}$ & Type B \\
& $10^{-4}$ & Type B \\
\hline
\end{tabular}

\subsection{Corrosion Testing}

Formation of the $\mathrm{Al}_{3} \mathrm{Mg}_{2}$ phase can be result in either stabilization or sensitization depending on the heat treatment temperature used $[1,2]$. In order for the stabilization heat treatment to be effective, it was necessary to determine at what temperature discreet $\mathrm{Al}_{3} \mathrm{Mg}_{2}$ particles were formed, but recrystallization was avoided. Therefore, microscopy was conducted on alloy 6 after rolling and 1-hour heat treatments at 200, 250, 300, and $350{ }^{\circ} \mathrm{C}$. Two collected SEM images of the alloy after the 200 and $250{ }^{\circ} \mathrm{C}$ heat treatments are shown in Figures 20 and 21, respectively. 


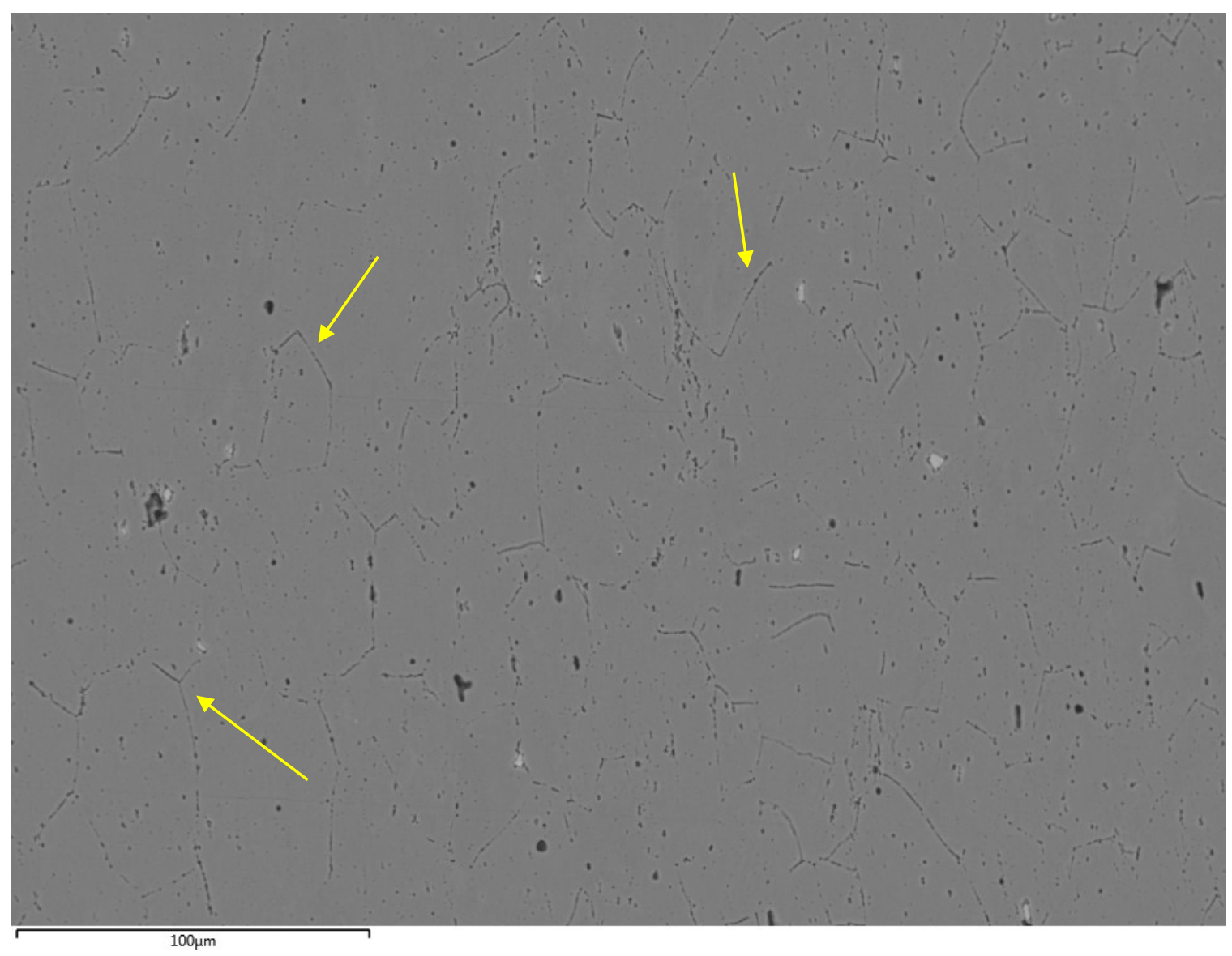

Figure 20. SEM micrograph of alloy 5 after rolling and heat treatment at 200 for 1 hour showing grain boundary sensitization. Examples of sensitized grain boundaries are marked by yellow arrows. 


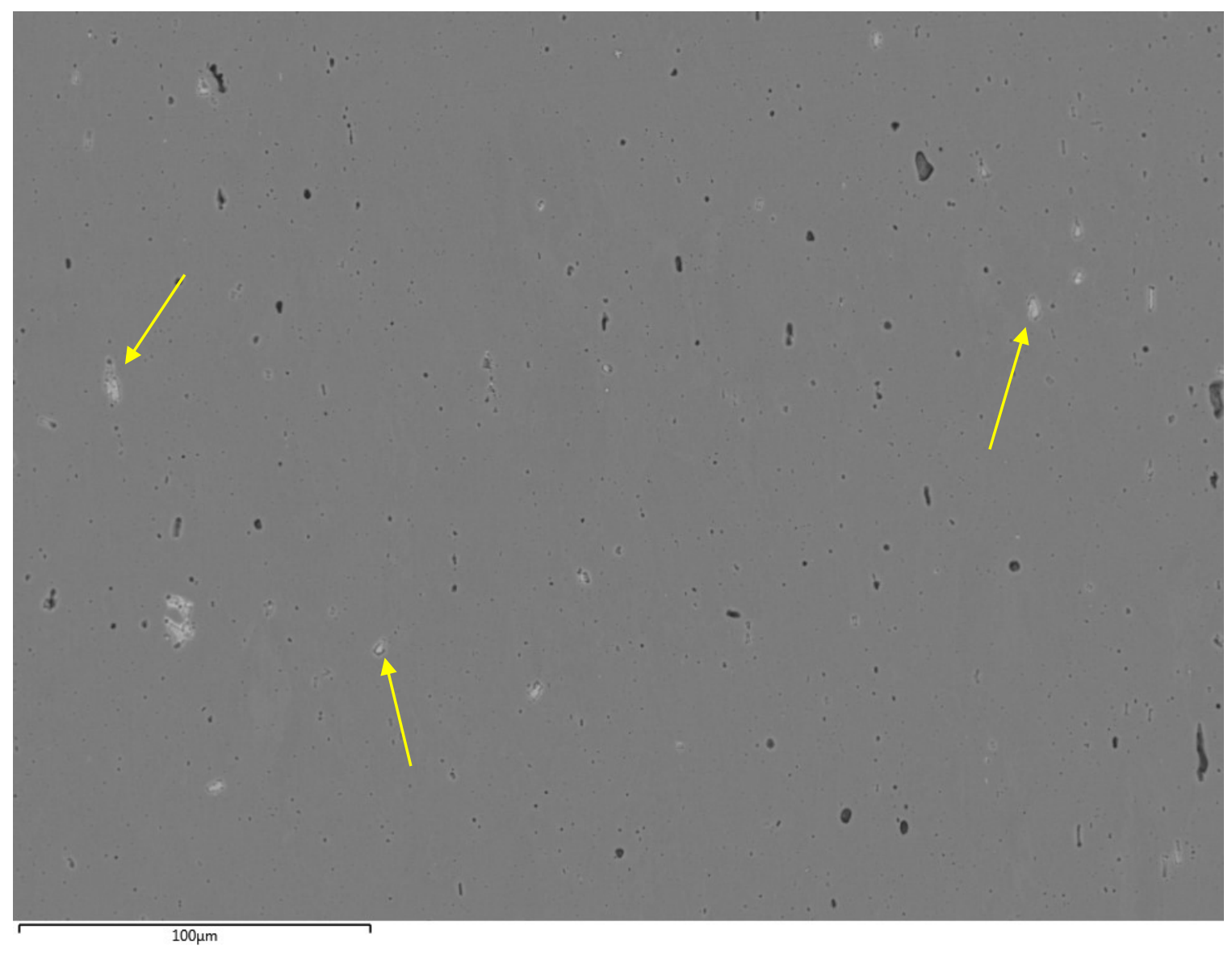

Figure 21. SEM micrograph of alloy 5 after rolling and heat treatment at 250 for 1 hour, showing no grain boundary sensitization.

From these images, it was seen that after $200^{\circ} \mathrm{C}$ for 1 hour, the alloy was sensitized, evidenced by the marked grain boundaries in Figure 16. Sensitization was not seen in the samples heat treated at higher temperatures, and as temperature increased, the likelihood of unintended recrystallization increased. Evidence of discreet $\mathrm{Al}_{3} \mathrm{Mg}_{2}$ was also found in the $250{ }^{\circ} \mathrm{C}$ sample, noted in Figure 21 by yellow arrows.

This information was used for selection of the 1 -hour $250{ }^{\circ} \mathrm{C}$ stabilization heat treatment.

As discussed in section 3.7.1, four different sample conditions were examined in the NAMLT test for each of the 6 alloys. A bar chart showing the mass loss results for Alloys 5 and 6 in each of these conditions is displayed in Figure 22. The other four alloys did not show significant intergranular corrosion. The tabulated corrosion rate results are displayed in Appendix A in Table A1. 


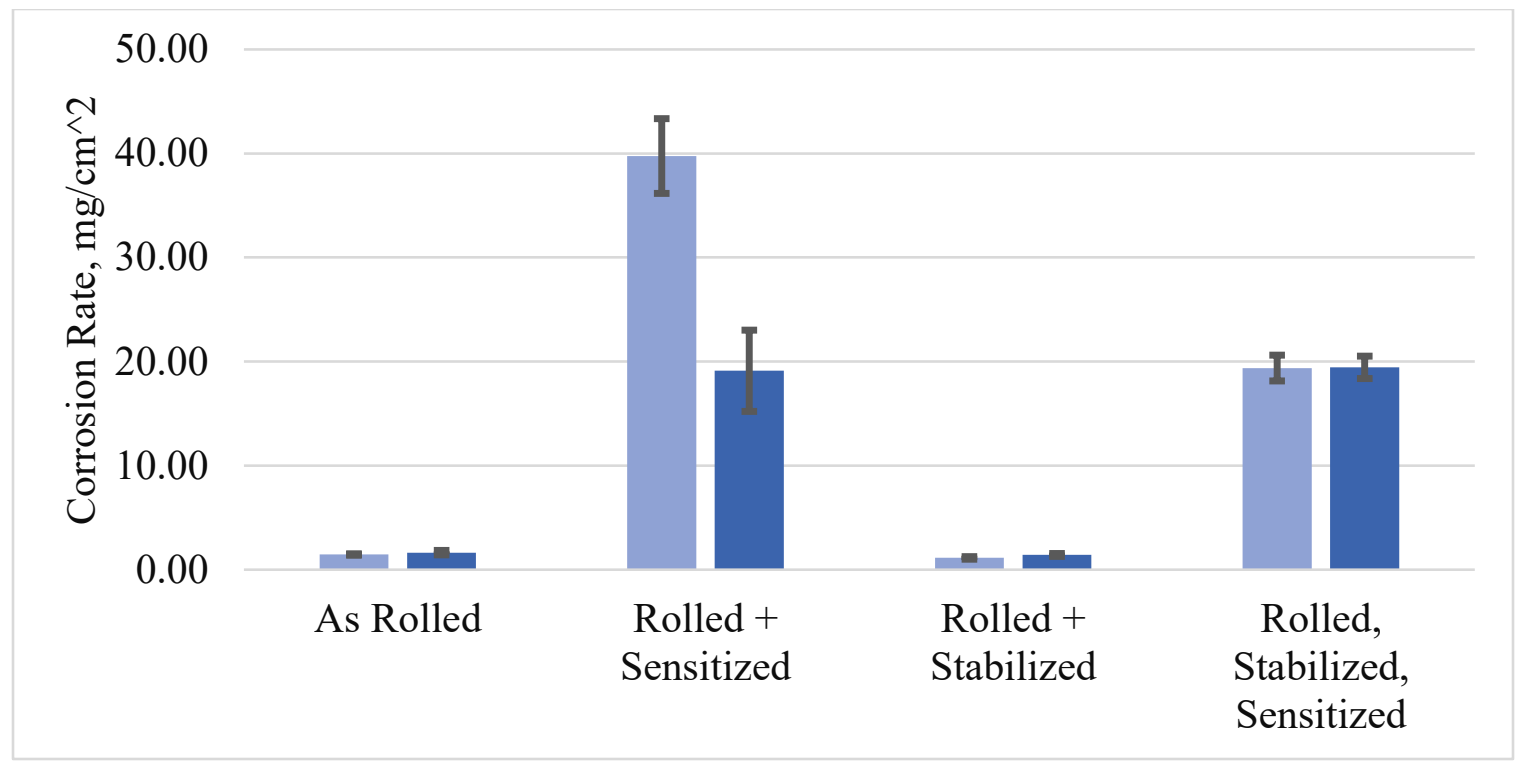

Figure 22. Corrosion rate results from NAMLT testing for alloys 5 and 6

In all conditions, alloys $1,2,3$, and 4 did not show large corrosion rates, likely due to a lack of sensitization in the alloys. However, alloys 5 and 6 showed relatively high corrosion rates in both conditions that had a sensitization treatment. Moreover, alloy 5 showed a significant improvement in corrosion rate when a stabilization heat treatment was included, whereas alloy 6 did not show significant improvement with the inclusion of the stabilization treatment. Also, the corrosion rate of alloy 5 when a stabilization and sensitization treatment were used was equivalent to the corrosion rate of alloy 6 in both sensitized conditions.

\subsection{TEM}

Results from TEM were focused largely on dispersoid size and distribution rather than structure. Brightfield images of dispersoids taken at Deakin University provided the information necessary to measure and compile these two data fields. Images of alloys 2, 4, and 6 after aging at are shown in Figures 23, 24, and 25 respectively. These images are representatives of the three alloys. 


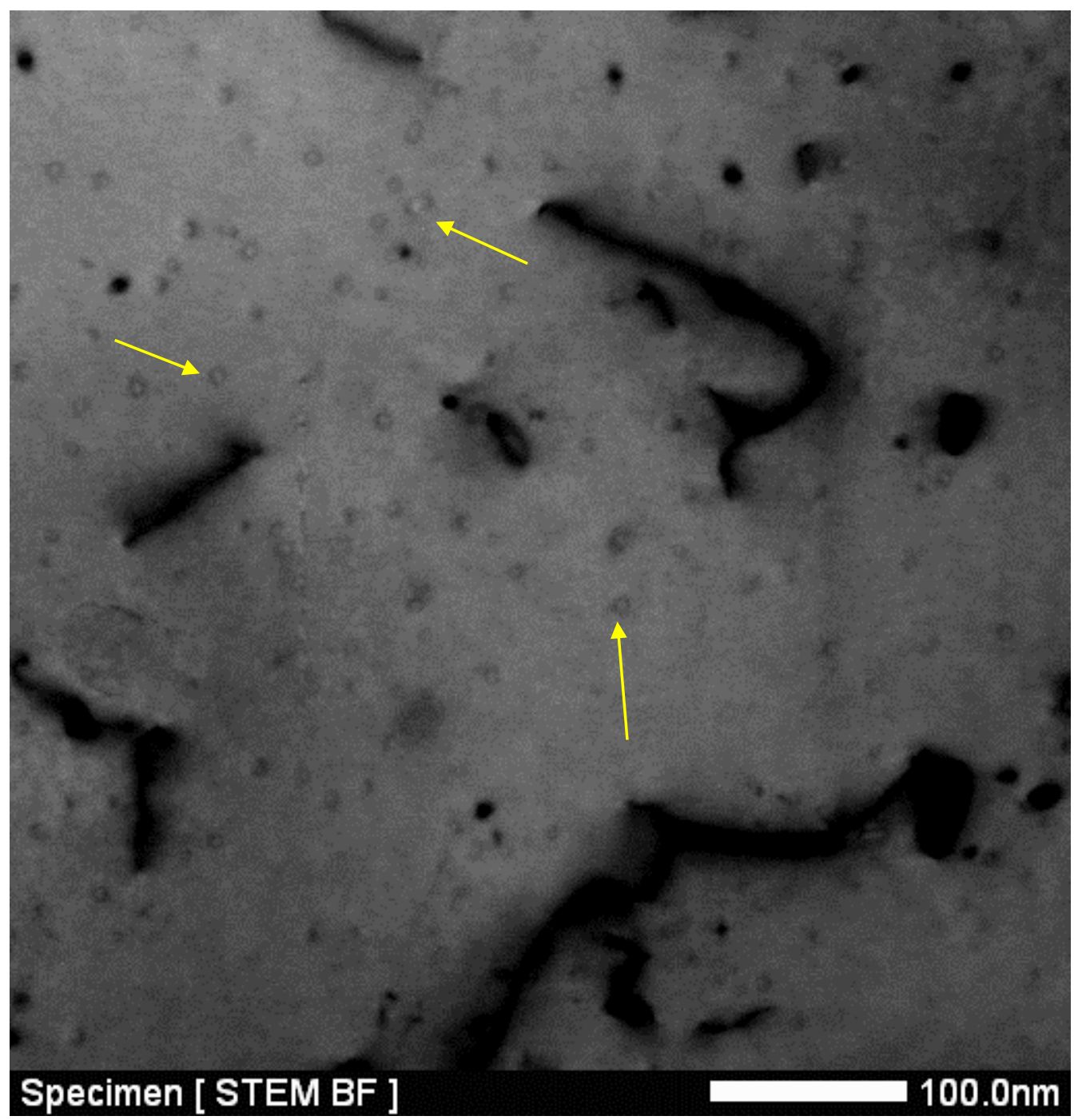

Figure 23. Brightfield TEM image of alloy 2 after heat treatment at $300{ }^{\circ} \mathrm{C}$ for 24 hours. Precipitates marked by yellow arrows. 


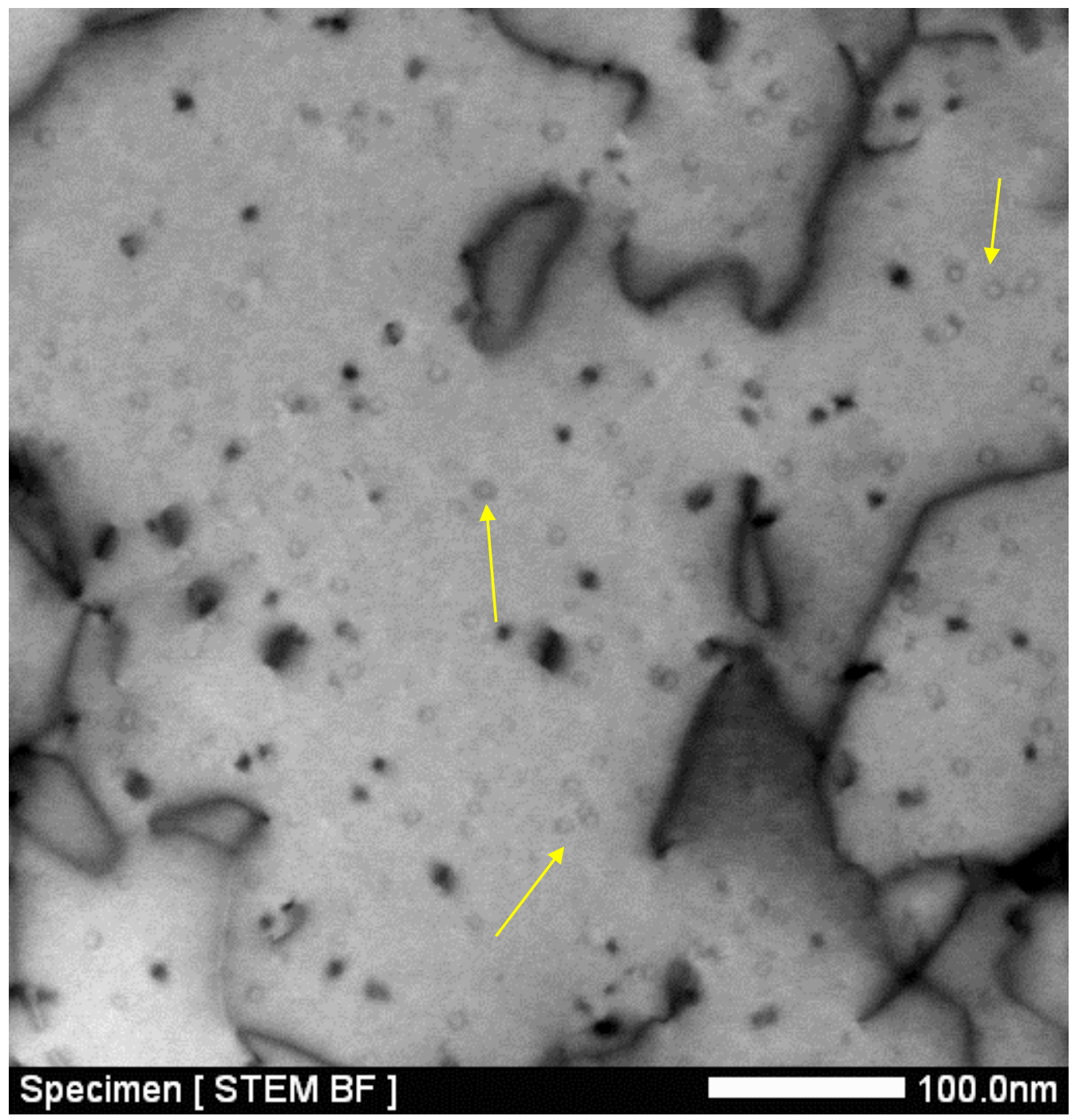

Figure 24. Brightfield TEM image of alloy 4 after heat treatment at $300{ }^{\circ} \mathrm{C}$ for 24 hours. Precipitates marked by yellow arrows. 


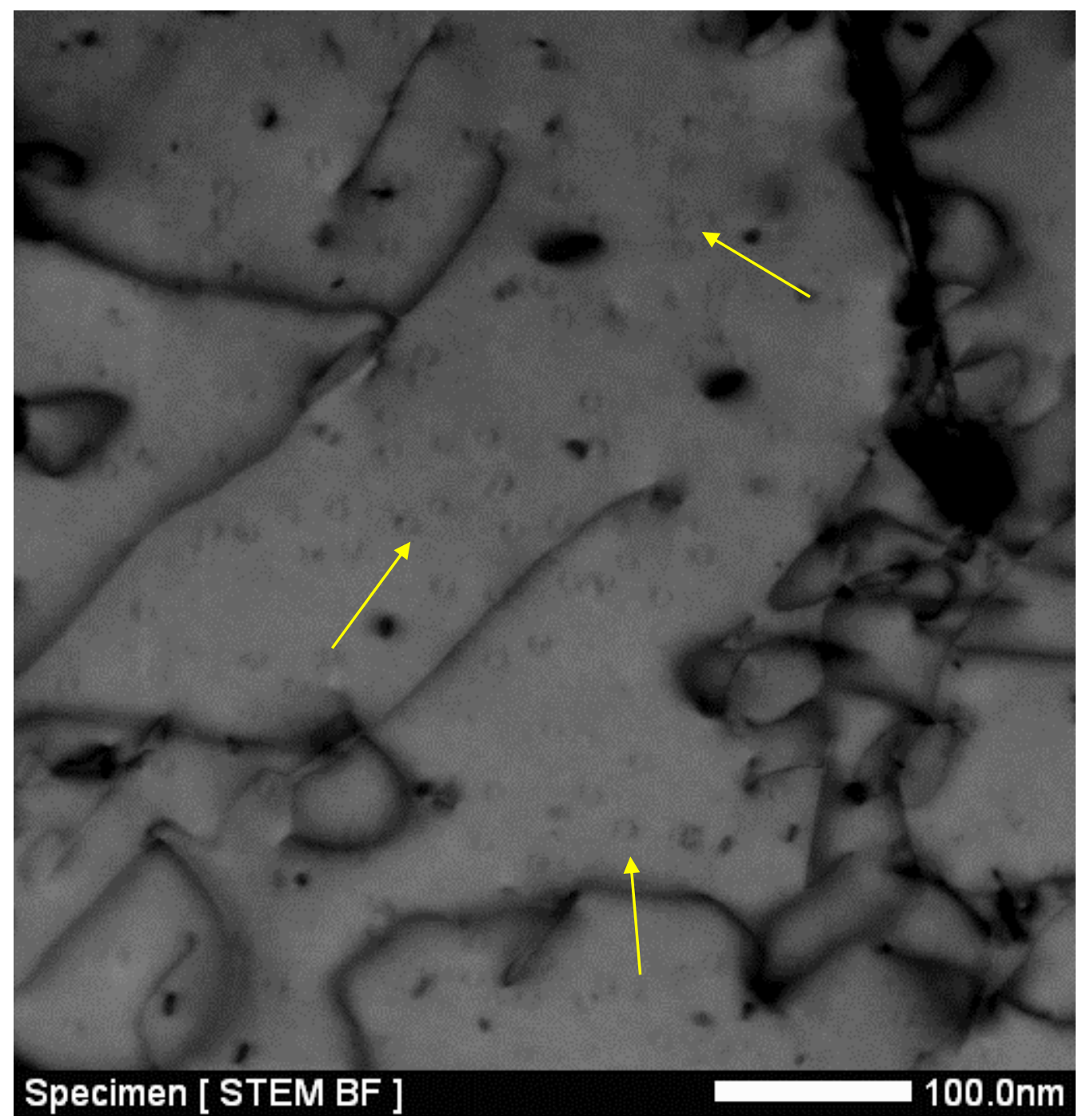

Figure 25. Brightfield TEM image of alloy 6 after heat treatment at $300{ }^{\circ} \mathrm{C}$ for 24 hours. Precipitates marked by yellow arrows.

In each of these images, the $\mathrm{Al}_{3} \mathrm{Sc}$ precipitates can be seen dispersed throughout the material as faint gray circular-shaped particles. Additionally, increasing amounts of dislocations can be identified by the long strings of dark material. There are some precipitates that do appear to form along these dislocations, however they are largely randomly dispersed. It should be noted that, possibly due to the low volume fraction of precipitates, darkfield analysis via selected diffraction was not possible with this material.

From the TEM images that were gathered, average $\mathrm{Al}_{3} \mathrm{Sc}$ particle size of the three alloys at each heat treatment was calculated using ImageJ software. Results of the particle size analysis are displayed in Table 9. 
Table 9. Average $\mathrm{Al}_{3} \mathrm{Sc}$ particle radii of analyzed samples with $95 \%$ confidence intervals

\begin{tabular}{|ccccc|}
\hline Alloy & $\begin{array}{c}\text { Heat Treatment } \\
\text { time at } 300{ }^{\circ} \mathrm{C}\end{array}$ & \multicolumn{3}{c|}{$\begin{array}{c}\text { Average Particle } \\
\text { Radius, } \mathrm{nm} \pm 95 \% \mathrm{CI}\end{array}$} \\
\hline 2 & 10 hours & 4.2 & \pm & 0.2 \\
& 24 hours & 4.6 & \pm & 0.2 \\
4 & 10 hours & 4.5 & \pm & 0.1 \\
& 24 hours & 4.9 & \pm & 0.2 \\
6 & 10 hours & 5.7 & \pm & 0.2 \\
& 24 hours & 6.1 & \pm & 0.2 \\
\hline
\end{tabular}

From Table 9, two trends are evident. The first is that the average $\mathrm{Al}_{3} \mathrm{Sc}$ particle radius increases with increasing $\mathrm{Mg}$ content for each heat treatment. Two-sample t-tests were conducted to test for statistical difference between particle radius each sample (6 individual tests) as well as between heat treatments for each sample (3 individual tests). In each case, differences in results were statistically significant $(\mathrm{p}<0.05)$.

A note should be made as to the uncertainty in particle radii measurements (physical rather than statistical). A consequence of the low volume fraction of $\mathrm{Al}_{3} \mathrm{Sc}$ precipitates, as well as the similarity in atomic weight between $\mathrm{Al}$ and $\mathrm{Sc}$ is that superlattice diffraction patterns from the ordered $\mathrm{L}_{2}$ precipitates, which are generally used to perform darkfield and diffraction analyses, were not capturable. As a result, only brightfield images of precipitates, such as the images shown above, were able to be captured. An inherent issue with brightfield imaging that darkfield imaging is able to overcome is the presence of image artifacts from strain and coherency effects surrounding the precipitates. As a result, in order to gather particle radii information, consistency in particle measuring technique was paid close attention. However, the issues with brightfield imaging herein remove some of the quantitative value of the precipitate radii measurements. 



\section{Discussion}

\subsection{Heat Treatment}

The isochronal and isothermal heat treatments presented in section 4.2 give insight into the nucleation and growth characteristics of the $\mathrm{Al}_{3}\{\mathrm{Sc}, \mathrm{Zr}\}$ precipitates, particularly with regard to any effect that $\mathrm{Mg}$ would have on the kinetics of the system.

The isochronal results presented before highlight two particular characteristics of precipitate development in the three Sc-containing alloys. Firstly, the large hardness increase associated with the $\mathrm{Al}_{3} \mathrm{Sc}$ nucleation occurs at the same temperature, $300{ }^{\circ} \mathrm{C}$, for all three alloys. What this suggests is that the nucleation and initial growth behavior of the $\mathrm{Al}_{3} \mathrm{Sc}$ precipitates is identical in all three alloys. As the only large variation between the three alloys is the Mg content, ranging from 1-5 weight percent, there is no clear effect from the $\mathrm{Mg}$ on nucleation kinetics of the Al-Sc system. Prior work completed on similar alloys showed mixed conclusions on whether Mg content had any such effect on this alloy system $[6,8]$, and the similar nucleation and initial growth results from hardness testing do not initially suggest major kinetic effects. However, as seen in Figure 1, higher $\mathrm{Mg}$ content reduces Sc solubility, leading to smaller precipitation strengthening.

Notable in both the isochronal and isothermal heat treatment results, particularly regarding the hardness measurements, is that the magnitude of hardening from precipitation decreased markedly from the Mg-lean to the Mg-rich alloys. In the $300{ }^{\circ} \mathrm{C}$ isothermal heat treatment, alloys 4 and 6 increased in hardness by about $6 \mathrm{HRF}$, whereas alloy 2 increased in hardness by about $22 \mathrm{HRF}$. A similar trend is seen in the isochronal heat treatment, whereby alloys 4 and 6 increased in hardness by similar magnitudes, but alloy 2 increased in hardness by a significantly higher magnitude. The cause of this relationship is discussed in section 5.4, relating the increasing size of $\mathrm{Al}_{3} \mathrm{Sc}$ particles to the decreasing Orowan strengthening from the particles. Further relation to the mechanical testing results will also be explored in sections 5.2 and 5.4.

The isothermal hardening behavior of each of the three alloys tested was very similar, with the initial aging peak being reached in each case after around 8 hours of heat treatment at $300{ }^{\circ} \mathrm{C}$ and little or no hardening occurring under continued heat treatment. This is due to the coarsening of precipitates during growth. It was discussed in section 2.1.2 that precipitation strengthening is most effective when particle sizes remain small, because as particle size increases, Orowan strengthening dominates and also continues to decrease [6], [10]. Another explanation lies in the changes in the coherency of particles. As coherent precipitates grow, so do the strain energy and interfacial energy associated with them. However, the interfacial energy is proportional to area, which is a non-linear proportionality, compared to the linear strain energy growth. As particles grow, interfacial energy dominates [19]. Additionally, anticoherency strains form and cancel out coherency strains present in smaller particles, reducing the strain energy [19]. 
Because of the competing strengthening mechanisms, hardness remains relatively constant during a significant growth period of the particles. Eventually, as seen in the isochronal hardness data in Figure 5, at sufficient heat treatment times or temperatures the particles lose coherency such that the strengthening is lost.

A noteworthy difference between the isochronal and isothermal heat treatment results is the difference in peak hardness and hardening increments between the two heat treatments. There are a number of causes for the higher peak hardness in isochronal aging. The first is that $300{ }^{\circ} \mathrm{C}$ is too low of a temperature to significantly precipitate $\mathrm{Al}_{3} \mathrm{Zr}$ during isothermal heat treatment, where the isochronal heat treatment was sufficient to precipitate both $\mathrm{Al}_{3} \mathrm{Sc}$ and $\mathrm{Al}_{3} \mathrm{Zr}$ phases. The second lies in the nucleation steps during isochronal heat treatment. At lower temperatures, nucleation and growth is a slower process, which can result in a greater number density of precipitates than at higher temperatures [19]. Because of this, during isochronal heat treatment there is prolonged low-temperature nucleation occurring. As precipitation hardening is greater when the number of precipitates is larger $[6,9]$ this contributes to a greater peak hardness as growth continues, as compared to the nucleation process at the higher temperature isothermal heat treatment.

A note should be made on the heat treatment that was used for the proceeding mechanical and corrosion testing materials, and the interaction with extrusion processing. The initial $300{ }^{\circ} \mathrm{C}$ heat treatment was done to precipitate the $\mathrm{Al}_{3} \mathrm{Sc}$ precipitates, and the following $400{ }^{\circ} \mathrm{C}$ step was done to precipitate the $\mathrm{Al}_{3} \mathrm{Zr}$. As was mentioned, a two stage heat treatment such as this creates a core-shell structure of $\mathrm{Al}_{3} \mathrm{Zr}$ around $\mathrm{Al}_{3} \mathrm{Sc}$ precipitates [5, 9]. Based on heat treatment results, the $\mathrm{Al}_{3} \mathrm{Zr}$ layer is much more thermally stable compared to the $\mathrm{Al}_{3} \mathrm{Sc}$, making the overall precipitate structure more robust under further thermomechanical processing. It was explained in section 3.4 that temperatures of the extruded billet and extrusion container were $450{ }^{\circ} \mathrm{C}$ and $425{ }^{\circ} \mathrm{C}$, respectively, during extrusion. These temperatures themselves are high enough to encourage precipitation of $\mathrm{Al}_{3} \mathrm{Sc}$ and $\mathrm{Al}_{3} \mathrm{Zr}$. Furthermore, during extrusion, the actual temperature of the billets will significantly exceed the preheated temperature. These effects, as well as the difficulty of precipitation after severe deformation, were the motivation for performing heat treatment before extrusion.

\subsection{Mechanical Testing}

The results of mechanical testing showed mixed effects of the development of $\mathrm{Al}_{3} \mathrm{Sc}$ precipitates on the PLC behavior but were able to show consistent strengthening trends throughout the 6 cast alloys, with varying strengthening increments on the yield strength of the materials.

By design, the 6 alloys produced were cast in 3 pairs, each pair having the same target $\mathrm{Mg}$ content and one of each pair having $\{\mathrm{Sc}, \mathrm{Zr}\}$ additions and $\mathrm{Al}_{3}\{\mathrm{Sc}, \mathrm{Zr}\}$ precipitates. A summary of the change in yield stress and ultimate stress at each Mg solute content level due to precipitation is shown in Table 10. 
Table 10. Summary of the increase in YS and UTS due to precipitation strengthening. $95 \%$ confidence intervals are shown.

\begin{tabular}{|ccccccc|}
\hline Alloys & \multicolumn{3}{c}{$\Delta \sigma_{\mathrm{YS}}, \mathrm{MPa}$} & \multicolumn{4}{c|}{$\Delta \sigma_{\mathrm{UTS}}, \mathrm{MPa}$} \\
\hline $1 \& 2$ & 78 & \pm & 2.4 & 91 & \pm & 0.2 \\
$3 \& 4$ & 118 & \pm & 5.7 & 78 & \pm & 2.8 \\
$5 \& 6$ & 126 & \pm & 0.2 & 81 & \pm & 1.4 \\
\hline
\end{tabular}

From the data in Table 9, the increase in yield strength due to precipitation increases as $\mathrm{Mg}$ content level increases. However, the UTS strengthening increment decreased from the Mg-lean to the Mg-rich alloys, similarly to the hardness increment behavior observed during isochronal and isothermal heat treatment. This again relates to the change in Orowan strengthening due to increasing precipitate size, discussed more in depth in section 5.4. The growing increase in yield strength, however, is attributed more to a different effect of the increasing $\mathrm{Mg}$ content and $\mathrm{Al}_{3} \mathrm{Sc}$ precipitates.

The atomic radius of $\mathrm{Mg}$ is larger than that of $\mathrm{Al}$, meaning that $\mathrm{Mg}$ atoms are substitutional in solid solution with $\mathrm{Al}$. Due to this, each $\mathrm{Mg}$ atom produces a compressive stress within the aluminum matrix, which hinders the movement of dislocations by either repelling or attracting compressive and tensile forces from the dislocations [6]. As a requisite for yielding of metals during deformation is the ability for dislocations to begin moving, increasing the solute content in $\mathrm{Al}-\mathrm{Mg}$ alloys leads to increases in the yield strength [6], [20].

The inclusion of $\mathrm{Al}_{3} \mathrm{Sc}$ precipitates creates additional stress fields around precipitates similar to solute atoms. Those stress fields in turn block dislocations from moving in the same manner. It was explained in section 2.1.2 that increasing Mg solute content leads to increased total volume fraction of precipitates. Given this, it could be explained that increasing $\mathrm{Mg}$ content, ergo increased precipitate amount, leads to growing yield strength increments in the observed alloys.

The variations in $\mathrm{Mg}$ content and $\mathrm{Al}_{3} \mathrm{Sc}$ precipitate development yielded varying results regarding the PLC effect behavior in the tested alloys. The goal in developing the $\mathrm{Al}_{3} \mathrm{Sc}$ precipitates was to mitigate certain PLC effect behaviors in an effort to understand how to improve the formability and deformation properties of Al-Mg alloys. The results of mechanical testing of alloys 1 and 2 show a reduction in the magnitude and frequency of stress instability in the presence of the $\mathrm{Al}_{3} \mathrm{Sc}$ precipitates. In the other four alloys, the results from the mechanical testing provided somewhat conflicting analysis. In the case of magnitude of stress serrations, in each case the Sc-containing alloys experienced magnitudes equal or greater than the Sc-free alloys; at a strain rate of $10^{-4} \mathrm{~s}^{-1}$, alloys 3 and 5 (Sc-free) showed serration magnitudes of about 5 and $9 \mathrm{MPa}$, respectively, while alloys 4 and 6 showed those of about 8 and 15, respectively. Reporting these serration magnitudes as a percentage of UTS, in order to normalize the magnitudes, gives 
percentages of 2.1 and 3.3 for alloys 3 and 5, versus 2.7 and 4.0 for alloys 4 and 6 . This increase in serration magnitude, whether absolute or normalized, indicates greater energy required for dislocation pinning and unpinning. This is a product of the additional strong dislocation obstacles created by the $\mathrm{Al}_{3}\{\mathrm{Sc}, \mathrm{Zr}\}$ precipitates as discussed in section 2.2, and is also indicative of a worsening in PLC behavior. However, alloy 4 showed an increase in Type A behavior over alloy 3 , and alloy 5 showed evidence of Type $\mathrm{C}$ behavior at early stages of plastic deformation that was not seen in alloy 6 . A zoomed view of the tensile curve displayed in section 4.3 for alloy 5 at the lower strain rate is displayed in Figure 26 to highlight the Type $\mathrm{C}$ behavior observed during early stages of plastic deformation.

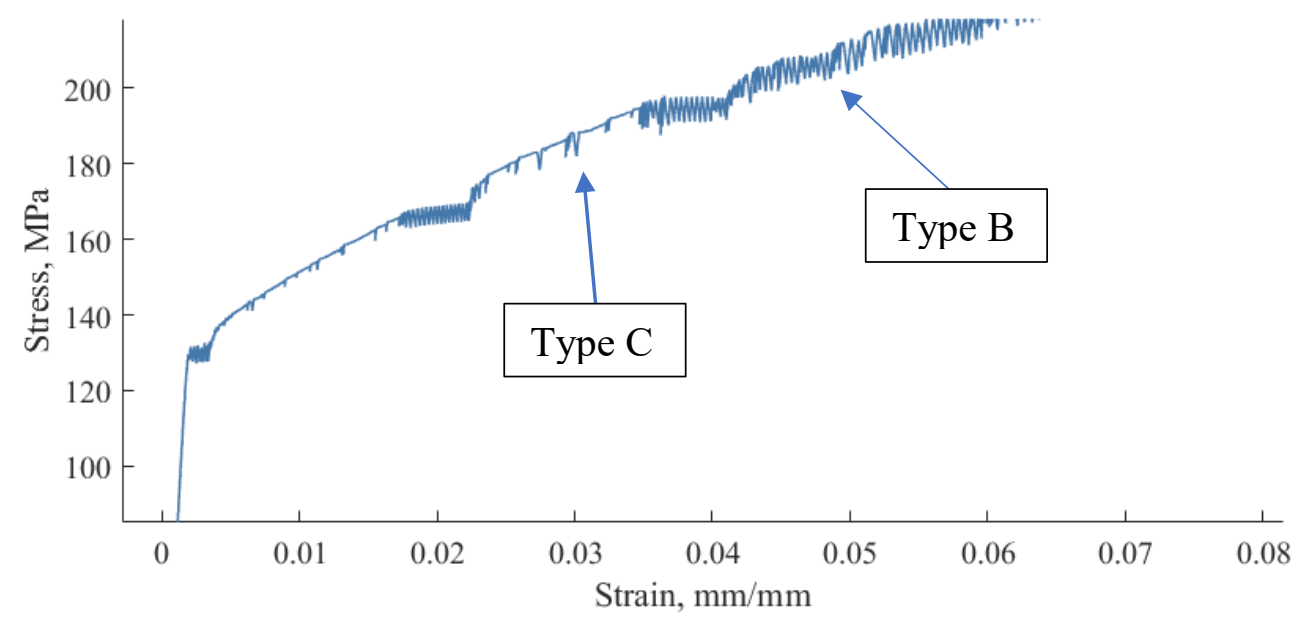

Figure 26. Enhanced view of stress vs. strain curve of alloy 5 sample at strain rate of $10^{-4}$ $\mathrm{s}^{-1}$. The two types of PLC serrations observed are marked.

As mentioned before, in terms of performance of materials and the detriments of PLC behavior, Type $\mathrm{C}$ behavior is regarded as the most detrimental, with Type $\mathrm{B}$ being considered less harmful and Type A being the most benign to material formability and performance. The mitigation of Type $\mathrm{C}$ behavior in the Mg-rich alloys due to precipitates then marks an improvement in the PLC behavior in those alloys.

The takeover of specific banding behaviors relates back to the physical explanation proposed in Section 2.2, wherein the presence of fine precipitates encourages the formation of bands in a propagating behavior rather than static, effectively working to homogenize plastic flow instability. It was explained that Type $\mathrm{C}$ behavior typically produces static stress serration banding $[3,14]$, and that this type of banding results in random, exaggerated bands within the material. The mitigation of the Type $\mathrm{C}$ behavior in the Mg-rich alloy when precipitates are present exemplifies this physical explanation. In addition, as Type $\mathrm{B}$ behavior is classified typically by hopping bands, in a sense very fast propagating, the takeover of Type A behavior in the intermediate Mg content alloys (outlined in Section 4.4) further indicates a homogenization of the banding propagation behavior. 
The two noted trends present contradictory evidence regarding the effect of $\mathrm{Al}_{3} \mathrm{Sc}$ precipitate development in improving the forming characteristics of $\mathrm{Al}-\mathrm{Mg}$ alloys, particularly as $\mathrm{Mg}$ level increases. The inclusion of $\mathrm{Al}_{3} \mathrm{Sc}$ precipitates does appear to drive a preference for less detrimental PLC behavior types, encouraging propagation of bands rather than static formation. However, there was a marked increase in stress serration magnitude in alloys 4 and 6 over their Sc-free alloy counterparts. Although $\mathrm{Al}_{3}\{\mathrm{Sc}, \mathrm{Zr}\}$ precipitates have the potential to homogenize strain during deformation, precipitates themselves act as additional barriers to dislocation motion, and therefore contribute to the strain energy necessary for unpinning of halted dislocations $[3,14]$. This is the reason for the apparent disagreement in effect of the precipitates on PLC behavior; the homogenization of plastic flow encourages less detrimental PLC behavior, but the presence of additional barriers encourages exaggerated stress serration magnitude.

\subsection{Corrosion Testing}

The issue of intergranular corrosion in Al-Mg alloys has been discussed, particularly with relation to the formation of continuous $\mathrm{Al}_{3} \mathrm{Mg}_{2}$ secondary phase particles along grain boundaries. Generally, sensitization does not occur significantly until $\mathrm{Mg}$ content exceeds around $3 \mathrm{wt} \%[1,2]$. Referring back to the composition results of casting presented in section 4.1, it was shown that the final $\mathrm{Mg}$ content in alloys 3 and 4 fell short of that mark, and alloys 1 and 2 had composition targets well below 3 weight percent $\mathrm{Mg}$. Therefore, alloys 5 and 6 were the only alloys that had enough $\mathrm{Mg}$ in solution to be very susceptible to thorough sensitization. This explains why the corrosion in alloys 1-4 was very low, with little variation between material processing conditions. Additionally, most of the analysis of samples after corrosion was focused on alloys 5 and 6, to explore the reasons for the variation in corrosion rate between the two alloys after sensitization treatments.

Corrosion rates for all alloys were presented in section 4.4, noting for alloys 5 and 6 that significant corrosion occurred after each alloy had undergone sensitization treatments after rolling, as well as after a stabilization and sensitization treatment (refer to Figure 3 in section 2.3 for difference between stabilization and sensitization). Most notably from the data, alloy 5, which had no inclusion of $\mathrm{Sc}$ or $\mathrm{Al}_{3} \mathrm{Sc}$ precipitates, saw significant improvement when a stabilization heat treatment was conducted prior to sensitization, but alloy 6 did not see any benefit from the stabilization heat treatment. Additionally, the performance of alloy 5 in the stabilized and sensitized condition was identical to that of alloy 6 in both mentioned conditions. In order to understand the cause of the variation in corrosion performance, SEM work was conducted on samples after corrosion testing was complete, to look for evidence of sensitization as well as grain structure in each sample. Several annotated SEM images of alloys 5 and 6 are presented in Figures 27-30, viewed normal to the extrusion/rolling direction of the material. 


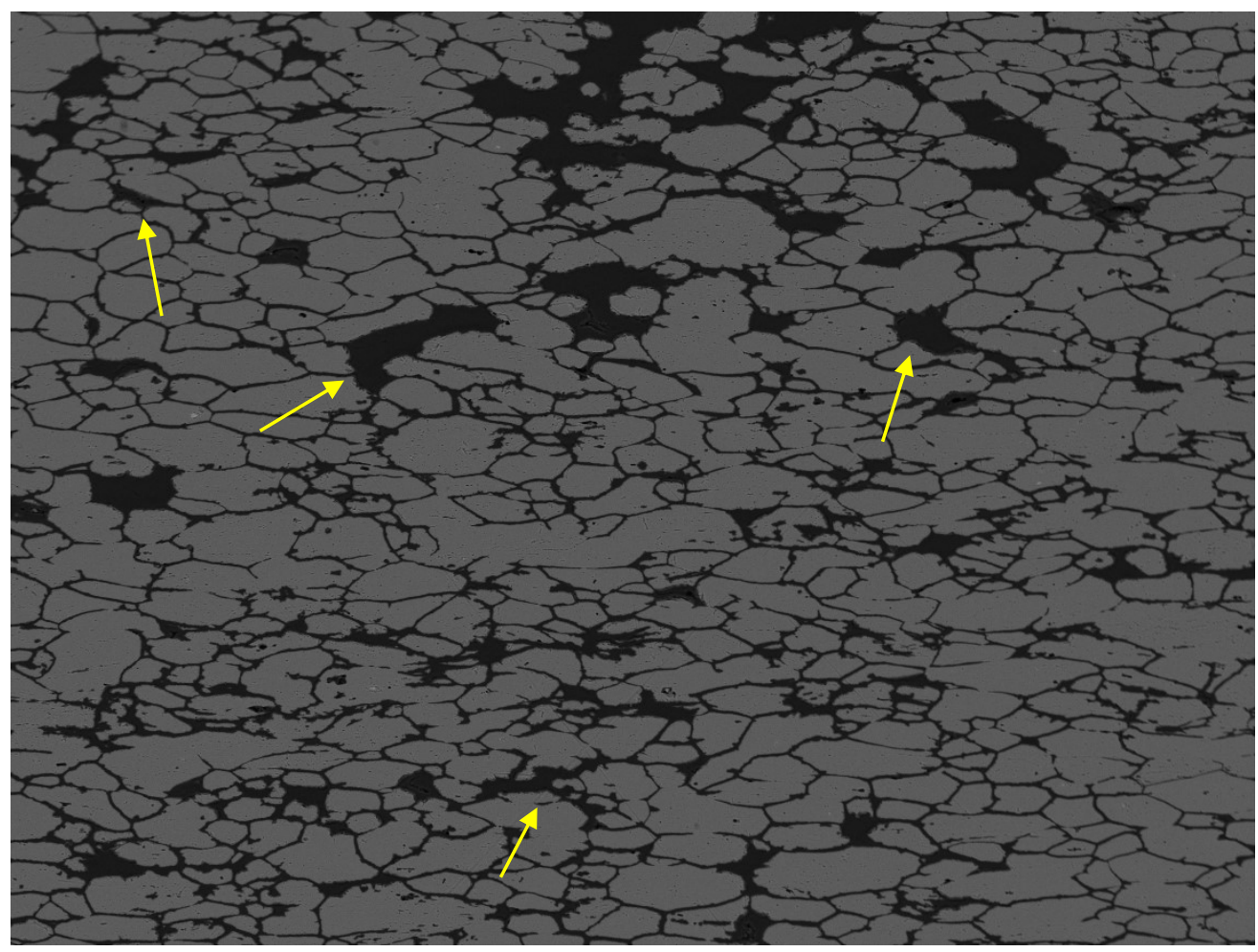

Figure 27. Alloy 5 in the rolled and sensitized condition. Heavy sensitization is visible along grain boundaries, marked by arrows. 


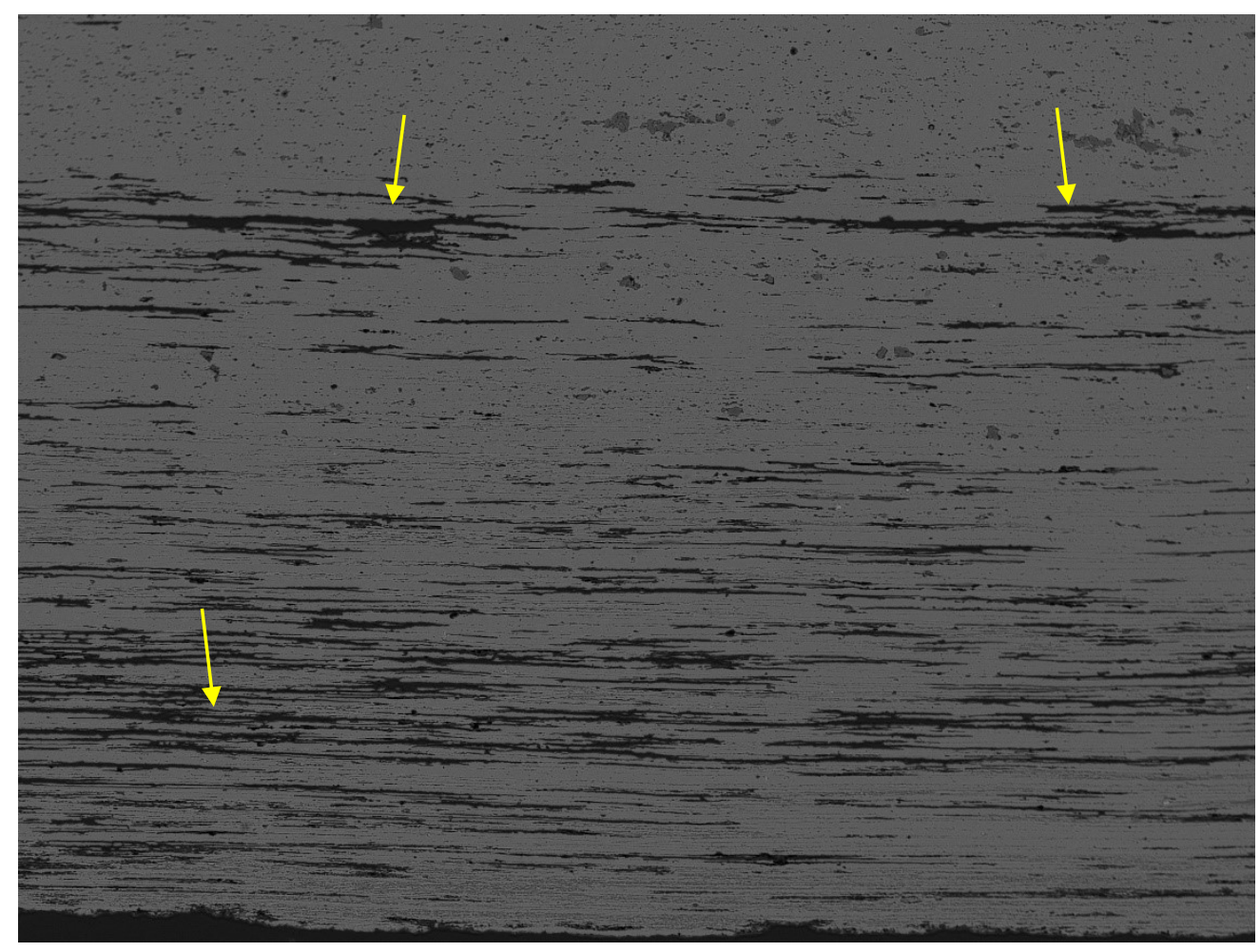

Figure 28. Alloy 6 in the rolled and sensitized condition. Fibrous grains with sensitization are visible, with sensitized areas shown in black and marked with arrows. 


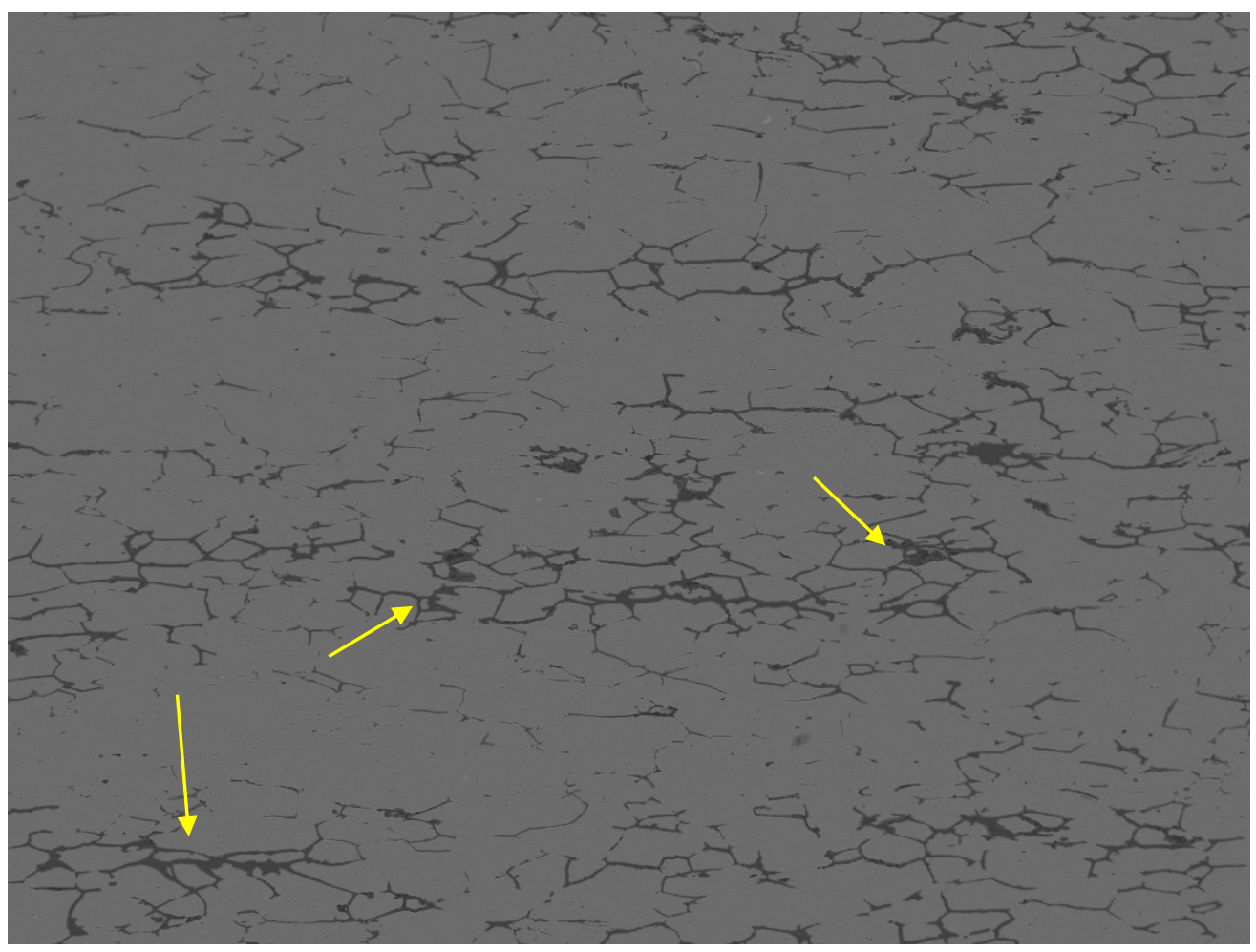

Figure 29. Alloy 5 in the rolled, stabilized, and sensitized condition. Grain boundaries are visible due to sensitization, marked by arrows. 


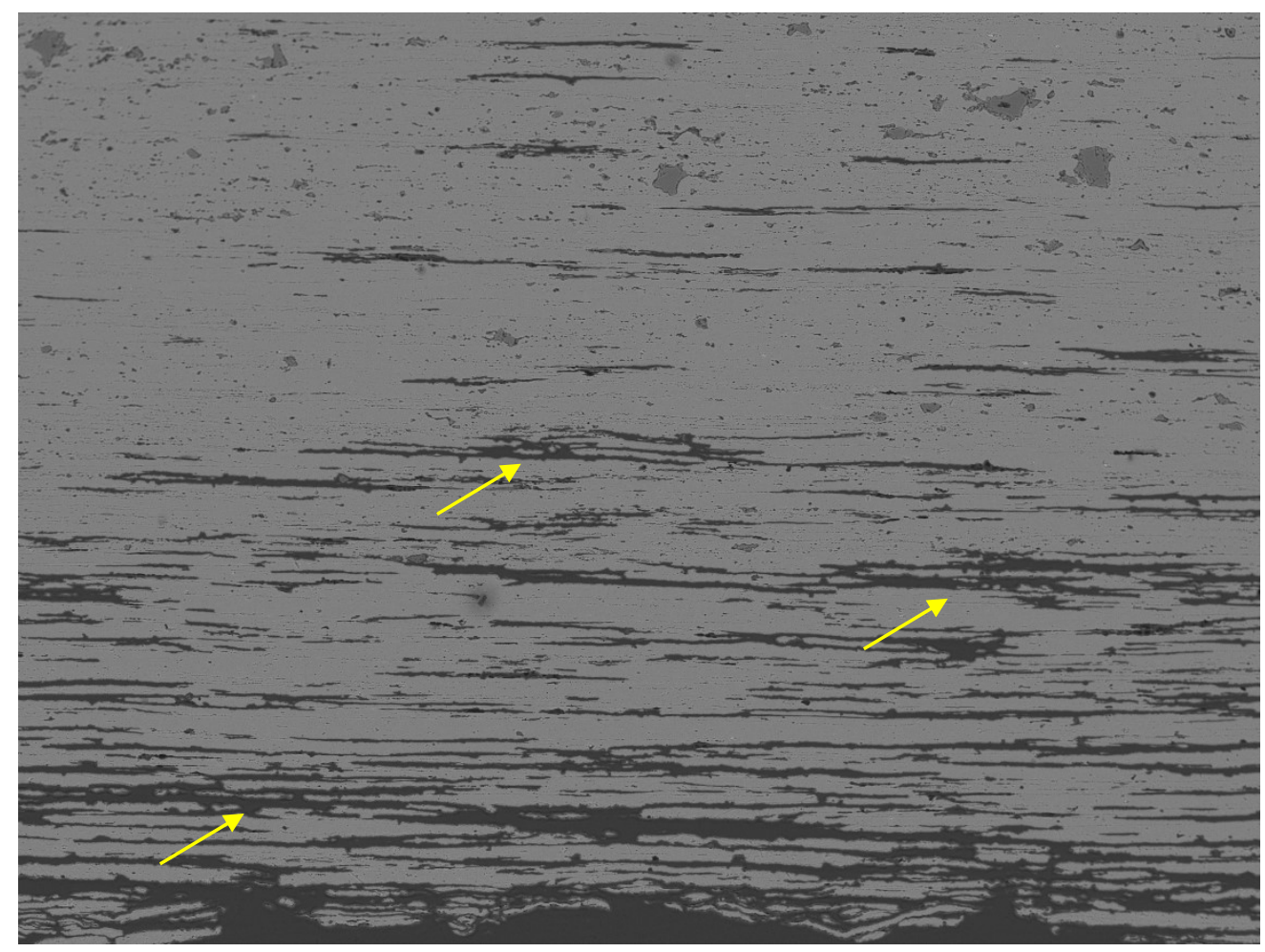

Figure 30. Alloy 6 in the rolled, stabilized, and sensitized condition. Fibrous grains with sensitization are visible, with sensitized areas shown in black and marked by arrows.

The SEM images show significant differences in grain structure between precipitate free and precipitate containing alloys, as well as differences in sensitization. Alloy 5 shows relatively large grains in both shown conditions, and the grain boundaries are clearly visible, where the continuous $\mathrm{Al}_{3} \mathrm{Mg}_{2}$ was corroded during testing. Considering the optical microscopy images presented in Section 4.2, in which alloys after rolling and a flash anneal showed highly elongated, non-recrystallized structures, it is evident that Alloy 5 underwent significant, if not complete, recrystallization during the applied corrosion study heat treatments. The lack of recrystallization is one of the bases of Hypothesis 2: finer grain structures increase the ratio of grain boundary area to grain volume, effectively reducing the portion of grain boundary area that can be sensitized. In this sense, Hypothesis 2 is confirmed. However, greater detail in explanation is available.

In alloy 5 , there is a visible difference in the extent of grain boundary sensitization when the stabilization was completed before hand, although the amount of recrystallization appears similar. This suggests that the stabilization treatment was successful in forming discreet $\mathrm{Al}_{3} \mathrm{Mg}_{2}$ particles that lessened the effect of the stabilization treatment, leading to the reduced corrosion rate observed. As discreet $\mathrm{Al}_{3} \mathrm{Mg}_{2}$ precipitates occupy a lower energy state than the continuous film formed during sensitization, there is a lack of driving force for the discreet particles to change morphology and form continuously along grain boundaries. However, in alloy 6 the stabilization treatment did not produce any improvement in corrosion rate, suggesting that formation of discreet $\mathrm{Al}_{3} \mathrm{Mg}_{2}$ was 
either unsuccessful or ineffective in reducing grain sensitization. From the SEM images of alloy 6 , the grain structure and sensitization level seem identical with and without a stabilization treatment. $\mathrm{As}_{3} l_{3}\{\mathrm{Sc}, \mathrm{Zr}\}$ precipitates are potent grain refiners [17], the grains in alloy 6 remained very fibrous. It is possible that the low energy grain boundaries did not provide enough energy for the formation of discreet precipitates, or that the large increase in grain boundary area to grain volume ratio simply dwarfed the effectiveness of stabilization in preventing subsequent sensitization. The refinement led to better sensitization resistance in alloy 6 , in which the increased grain boundary area to volume ratio improved resistance to intergranular corrosion.

\subsection{TEM}

Analysis of $\mathrm{Al}_{3} \mathrm{Sc}$ precipitates via TEM focused on precipitate size differences as evidence of the effect increasing Mg content on precipitation. It was shown in the hardness results from heat treatment testing that nucleation appeared unaffected by $\mathrm{Mg}$ content, however the decrease in strengthening increment suggested some effect on the precipitates. From the TEM analysis, it is evident that higher $\mathrm{Mg}$ content consistently causes $\mathrm{Al}_{3} \mathrm{Sc}$ precipitates to form at larger sizes. If $\mathrm{Mg}$ solute clusters do indeed act as nucleation sites, it would be expected that nucleation behavior between the three Sccontaining alloys would be varied, which was not observed.

The strengthening mechanisms behind the Al-Sc system were discussed in section 2.1.1. It was explained that strength from the $\mathrm{Al}_{3} \mathrm{Sc}$ precipitates is rooted largely in the Orowan mechanism, due to the very small precipitate sizes required for cutting strengthening to dominate [10]. It was also discussed that continued increases in particle size reduce the Orowan strengthening. A diagram of the relationship between particle size and strengthening mechanism is shown in Figure 31. As precipitate size increases, a critical radius, which for $\mathrm{Al}_{3} \mathrm{Sc}$ precipitates is around 1-3 nm [10], is reached, after which continuous particle growth results in further dominance of Orowan strengthening $[6,7$, $10]$. 


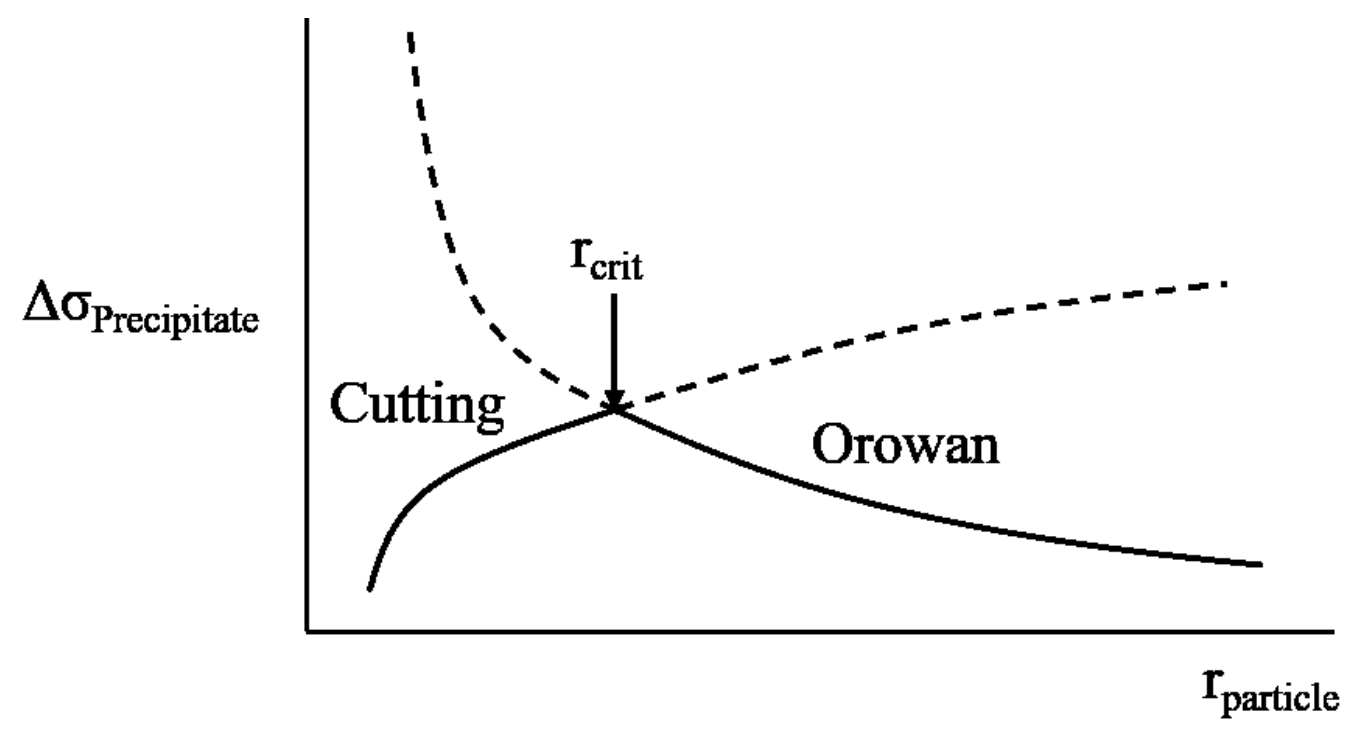

Figure 31. Diagram of precipitation strengthening increment and source as a function of particle size. The critical radius at which Orowan strengthening begins to dominate is marked.

This consequence connects the increased precipitate size and changing hardening increment seen with increasing Mg content. Using the measured precipitate radii and equations 2.1-2.3, values for cutting strengthening and Orowan strengthening were calculated. Values for material constants were taken from [21], and are displayed in Table 11 along with the parameter meanings. Precipitate volume fraction was calculated using a single-point equilibrium calculation in ThermoCalc software.

Table 11. Literature values for constants used in strengthening equations.

\begin{tabular}{|ccc|}
\hline Constant & Paramater & Value \\
\hline $\mathrm{f}$ & Precipitate Volume Fraction & 0.0019 \\
$\mathrm{~b}$ & Burger's Vector & $2.86 \AA$ \\
$\mathrm{M}$ & Taylor Factor & 3.06 \\
$\mathrm{G}_{\mathrm{M}}$ & Matrix Shear Modulus & $25.4 \mathrm{GPa}$ \\
$\mathrm{G}_{\mathrm{Al} 3 \mathrm{Sc}}$ & Precipitate Shear Modulus & $67.9 \mathrm{GPa}$ \\
$v_{\mathrm{N}}$ & Poisson's Ratio & 0.34 \\
$\gamma_{\mathrm{APB}}$ & Anti-Phase Boundary Energy & $0.5 \mathrm{~J} / \mathrm{m}^{2}$ \\
\hline
\end{tabular}

Using the literature values in Table 11 and Equations 2.2 and 2.3, estimated Orowan strengthening values for each alloy at both heat treatment conditions were calculated, and are displayed in Table 12. At the measured particle radii in each sample, the estimated cutting strengthening values were roughly 10 orders of magnitude higher than the Orowan values, and therefore were excluded from Table 12 because Orowan 
strengthening is the minimized, and therefore dominant, strengthening mechanism per section 2.1.1.

Table 12. Estimated Orowan strengthening values for alloys 2, 4, and 6 after heat treatments at $300 \mathrm{C}$.

\begin{tabular}{|ccc|}
\hline Alloy & $\begin{array}{c}\text { Heat Treatment } \\
\text { Time }\end{array}$ & Orowan Strength, MPa \\
\hline \multirow{2}{*}{2} & 10 & $579 \pm 13$ \\
& 24 & $552 \pm 16$ \\
4 & 10 & $554 \pm 11$ \\
& 24 & $521 \pm 11$ \\
6 & 10 & $436 \pm 10$ \\
& 24 & $423 \pm 8$ \\
\hline
\end{tabular}

Estimation of the Orowan strengthening increment involves some key assumptions. The first is that the volume fraction of precipitates is accurate according to the ThermoCalc calculation of each alloy at the given heat treatment temperature and time; the second is that the spacing between particles is constant throughout the material [6]. In reality, the volume fraction achieved is much lower, and thus the error associated with these measurements (not the shown propagated error, rather that the numbers are not quantitatively accurate) is relatively large. Additionally, the dispersion of precipitates throughout the material is not constant, and there are relatively large volumes of precipitate-free material. The deviation from assumptions is reflected in the fact that the magnitude of estimated Orowan strengthening is much larger than the observed improvements in hardness and strength in the materials. However, it is evident that the predicted Orowan strengthening decreases as $\mathrm{Mg}$ content increases, due to the increase in precipitate size. This result relates to the diminishing hardening increment observed in the isochronal and isothermal heat treatment results as well as the diminishing UTS hardening increment as $\mathrm{Mg}$ solute content is increased.

According to the explanation given in section 2.1.2, as $\mathrm{Mg}$ solute content is increased, the equilibrium volume fraction of $\mathrm{Al}_{3} \mathrm{Sc}$ is increased. This is evidenced experimentally by the measured increase in precipitate size from TEM analysis. This increase in precipitate radii in turn, as shown in Table 9, reduces the associated Orowan strengthening for each alloy [6]. As Orowan strengthening is an interpretation largely of plastic flow strength [6], decreases in Orowan strengthening should lead to decreases in UTS. This trend is seen between alloys 2, 4, and 6, where the Mg-lean alloy produces a significantly larger ( $\sim 10 \mathrm{MPa}$ ) UTS increase compared to the other two. This trend was also seen in the hardness measurements from heat treatments presented above, wherein alloy 2 saw significantly larger hardening increments than alloys 4 and 6, which produced similar hardening increments to eachother. Thus, the physically observed increase in particle radii and strengthening trends are linked to the Orowan strengthening model. 
An interesting note in the UTS and hardening increments is the equivalent results between alloys 4 and 6, despite the significant difference in measured particle size between the two alloys. One explanation of this is the plateau of Orowan strengthening as particle size continues to increase, as seen in Figure 30. Continual growth in precipitate size produces diminishing returns on Orowan strengthening increment. Additionally, from the cast alloy compositions presented in Section 4.1, alloy 4 had a higher Si content than the other cast alloys. In the hardness results from isochronal heat treatment presented in Section 4.2, an increase in hardness at $200{ }^{\circ} \mathrm{C}$ indicated some formation the strengthening $\mathrm{Mg}_{2} \mathrm{Si}$ phase that forms in elevated $\mathrm{Mg}$ and $\mathrm{Si}$ solute contents. These could have contributed to the equivalency in strengthening behavior between alloys 4 and 6 , however the connection between strengthening trends and the Orowan strengthening model are still apparent. 



\section{Conclusions}

The analysis of heat treatment, microscopy, mechanical testing, and corrosion testing of the Al-Mg-Sc provided results on two proposed hypotheses regarding mechanical properties and corrosion behavior of this alloy system. Further evaluation of $\mathrm{Al}_{3} \mathrm{Sc}$ precipitates yielded findings on the effect of $\mathrm{Mg}$ solute content on the precipitate formation and growth and offers some explanation of the decrease in precipitation strengthening increment as solute content increases. Additionally, the results point the direction for future work in evaluating the Al-Mg-Sc alloy system.

The first hypothesis proposed that development of these precipitates could serve to homogenize strain during deformation and thereby mitigate and improve the stress-strain instability associated with the PLC effect commonly seen in Al-Mg alloys via encouragement of propagation-type stress banding over static banding. Results of mechanical testing showed that while the more detrimental, static banding behavior modes of the PLC effect were improved or mitigated altogether due to development of $\mathrm{Al}_{3} \mathrm{Sc}$ precipitates, the magnitude of stress variation during serrated plastic flow was not improved. This result suggests that, although the behavior of dislocation arresting and freeing was improved, the stress necessary for unpinning of dislocation movement is increased by the precipitates. Given that the performance severity of PLC effect is dependent more on banding mode than severity, these results suggest an interplay of beneficial and detrimental PLC behavior.

The second hypothesis proposed that development of $\mathrm{Al}_{3} \mathrm{Sc}$ precipitates could help mitigate the effects of grain boundary sensitization in Mg-rich aluminum alloys by refining the grain structure during deformation and preventing recrystallization, both of which lead to increased grain boundary area per sample volume. Results of a standard NAMLT corrosion test found that the presence of $\mathrm{Al}_{3} \mathrm{Sc}$ precipitates caused significant reduction in corrosion in Al-Mg samples that had been sensitized after cold work. However, the inclusion of a stabilization heat treatment produced similar improvements in corrosion resistance in a Sc-free Al-Mg alloy. Furthermore, the inclusion of a stabilization heat treatment had no effect on the corrosion of a Sc-containing alloy after sensitization. Further SEM work highlighted the improvement in sensitization in the Scfree alloy due to a stabilization treatment, as well as the ability of the fine grain structure due to $\mathrm{Al}_{3} \mathrm{Sc}$ precipitates to prevent thorough sensitization of the Al-Mg alloys.

The results and analysis of TEM research showed a marked increase in $\mathrm{Al}_{3} \mathrm{Sc}$ precipitate size as a result of increasing additions of $\mathrm{Mg}$ to the alloys, while the hardness measurements from heat treatment saw large decreases in precipitation strengthening increment with increased $\mathrm{Mg}$ solute content. This increase in precipitate size causes a reduction in the Orowan strengthening and could also cause coarsening issues. Additionally, the decrease in precipitate solubility and increase in precipitate size at higher $\mathrm{Mg}$ solute content suggests a reduction in the precipitate volume fraction that 
would further reduce the strengthening from precipitation. The TEM results point the way for future work on the morphology and distribution of $\mathrm{Al}_{3} \mathrm{Sc}$ precipitates with varied Mg content.

The focus of the hypotheses and experimentation has been on the processing, properties, and structure of the alloys that were studied. However, drawing those three leads to a conclusion on the overall performance of $\mathrm{Al}-\mathrm{Mg}$ alloys with the development of $\mathrm{Al}_{3} \mathrm{Sc}$ precipitates. As has been mentioned, there are known characteristics of Al-Mg alloys, namely the PLC effect and intergranular corrosion, that are undesirable in application. Furthermore, the development of precipitate structures in metals is based around strengthening of the material. Given this information, a benchmark for an alloy to be developed from this work would be to have strength from $\mathrm{Al}_{3} \mathrm{Sc}$ precipitates that would enable the reduction of $\mathrm{Mg}$ solid solution to avoid intergranular corrosion. In the case of alloy 4, the Mg content is sufficiently low that sensitization did not occur, and corrosion levels were low, and the strength characteristics exceeded those of alloy 5, which had $\sim 2$ weight percent additional $\mathrm{Mg}$ solute content and was highly susceptible to sensitization and intergranular corrosion. Additionally, the PLC behavior at lower Mg content experiences lower stress serration magnitude and more seldom occurrence of the more severe PLC behavior types. This conclusion points toward the development of highperformance Al-Mg alloys that can avoid some of the issues associated with high $\mathrm{Mg}$ solute content through the use of $\mathrm{Al}_{3} \mathrm{Sc}$ precipitates. 


\section{References}

[1] R. Zhang, S. P. Knight, R. L. Holtz, R. Goswami, C. H. J. Davies, and N. Birbilis, "A Survey of Sensitization in 5xxx Series Aluminum Alloys," Corrosion, vol. 72, no. 2, pp. 144-159, Feb. 2016.

[2] L. Kramer, M. Phillippi, W. T. Tack, and C. Wong, "Locally Reversing Sensitization in 5xxx Aluminum Plate," J. Mater. Eng. Perform., vol. 21, no. 6, pp. 1025-1029, Jun. 2012.

[3] A. Yilmaz, "The Portevin-Le Chatelier effect: a review of experimental findings," Sci. Technol. Adv. Mater., vol. 12, no. 6, p. 063001, Dec. 2011.

[4] V. V. Zakharov, "Combined Alloying of Aluminum Alloys with Scandium and Zirconium," Met. Sci. Heat Treat., vol. 56, no. 5-6, pp. 281-286, Sep. 2014.

[5] E. A. Marquis and D. N. Seidman, "Nanoscale structural evolution of A13Sc precipitates in $\mathrm{Al}(\mathrm{Sc})$ alloys," Acta Mater., vol. 49, no. 11, pp. 1909-1919, Jun. 2001.

[6] J. Rösler, H. Harders, and M. Bäker, Mechanisches Verhalten der Werkstoffe: mit 31 Tabellen und 34 Aufgaben und Lösungen, 2., durchges. und erw. Aufl. Wiesbaden: Teubner, 2006.

[7] C. B. Fuller, A. R. Krause, D. C. Dunand, and D. N. Seidman, "Microstructure and mechanical properties of a 5754 aluminum alloy modified by Sc and $\mathrm{Zr}$ additions," Mater. Sci. Eng. A, vol. 338, no. 1-2, pp. 8-16, Dec. 2002.

[8] K. Deane, "INVESTIGATION AND MODELING OF Al3(Sc, Zr) PRECIPITATION STRENGTHENING IN THE PRESENCE OF ENHANCED SUPERSATURATION AND WITHIN Al-Cu BINARY ALLOYS,” p. 221.

[9] K. E. Knipling, R. A. Karnesky, C. P. Lee, D. C. Dunand, and D. N. Seidman, "Precipitation evolution in Al-0.1Sc, Al-0.1Zr and Al-0.1Sc-0.1Zr (at.\%) alloys during isochronal aging," Acta Mater., vol. 58, no. 15, pp. 5184-5195, Sep. 2010.

[10] K. Deane, S. L. Kampe, D. Swenson, and P. G. Sanders, "Precipitate Evolution and Strengthening in Supersaturated Rapidly Solidified Al-Sc-Zr Alloys," Metall. Mater. Trans. A, vol. 48, no. 4, pp. 2030-2039, Apr. 2017.

[11] Yu. Buranova et al., "Al 3 (Sc,Zr)-based precipitates in Al-Mg alloy: Effect of severe deformation," Acta Mater., vol. 124, pp. 210-224, Feb. 2017.

[12] E. A. Marquis, D. N. Seidman, and D. C. Dunand, "Effect of Mg addition on the creep and yield behavior of an Al-Sc alloy," Acta Mater., vol. 51, no. 16, pp. 47514760, Sep. 2003.

[13] S. Ikeshita et al., "Hardness and microstructural variation of $\mathrm{Al}-\mathrm{Mg}-\mathrm{Mn}-\mathrm{Sc}-\mathrm{Zr}$ alloy," Micron, vol. 82, pp. 1-8, Mar. 2016.

[14] D. A. Zhemchuzhnikova, M. A. Lebyodkin, T. A. Lebedkina, and R. O. Kaibyshev, "Unusual behavior of the Portevin-Le Chatelier effect in an AlMg alloy containing precipitates," Mater. Sci. Eng. A, vol. 639, pp. 37-41, Jul. 2015.

[15] Y. Brechet and Y. Estrin, "On the influence of precipitation on the Portevin-Le Chatelier effect," Acta Metall. Mater., vol. 43, no. 3, pp. 955-963, Mar. 1995.

[16] Q. Hu, Q. Zhang, S. Fu, P. Cao, and M. Gong, "Influence of precipitation on the Portevin-Le Chatelier effect in Al-Mg alloys," Theor. Appl. Mech. Lett., vol. 1, no. 1, p. $011007,2011$. 
[17] V. Fallah, A. Howells, M. F. Gallerneault, and W. M. T. Gallerneault, "CONTROL OF RECRYSTALLIZATION IN COLD-ROLLED AlMn(Mg)ScZr SHEET FOR BRAZING APPLICATIONS," p. 9.

[18] M. Mohammadtaheri, "A New Metallographic Technique for Revealing Grain Boundaries in Aluminum Alloys," Metallogr. Microstruct. Anal., vol. 1, no. 5, pp. 224-226, Oct. 2012.

[19] R. W. Balluffi, S. M. Allen, W. C. Carter, and R. A. Kemper, Kinetics of materials. Hoboken, N.J: J. Wiley \& Sons, 2005.

[20] Ø. Ryen, B. Holmedal, O. Nijs, E. Nes, E. Sjölander, and H.-E. Ekström, "Strengthening mechanisms in solid solution aluminum alloys," Metall. Mater. Trans. A, vol. 37, no. 6, pp. 1999-2006, Jun. 2006.

[21] D. N. Seidman, E. A. Marquis, and D. C. Dunand, "Precipitation strengthening at ambient and elevated temperatures of heat-treatable $\mathrm{Al}(\mathrm{Sc})$ alloys," Acta Mater., vol. 51, no. 1, pp. 285-287, Jan. 2003. 


\section{Appendix A}

Table A1. Tabulated NAMLT corrosion results for each alloy and condition. Uncertainties given by standard deviations.

\begin{tabular}{|c|c|c|c|c|}
\hline \multirow[t]{2}{*}{ Alloy } & \multirow{2}{*}{$\begin{array}{l}\text { Condition } \\
\text { As Rolled }\end{array}$} & \multicolumn{3}{|c|}{ Average Mass Loss $\left(\mathrm{mg} / \mathrm{cm}^{\wedge} 2\right)$} \\
\hline & & 1.07 & \pm & 0.07 \\
\hline \multirow{3}{*}{1} & Rolled + Sensitized & 1.07 & \pm & 0.14 \\
\hline & Rolled + Stabilized & 1.23 & \pm & 0.00 \\
\hline & Rolled, Stabilized, Sensitized & 0.81 & \pm & 0.07 \\
\hline \multirow{4}{*}{2} & As Rolled & 0.91 & \pm & 0.07 \\
\hline & Rolled + Sensitized & 1.03 & \pm & 0.07 \\
\hline & Rolled + Stabilized & 1.07 & \pm & 0.14 \\
\hline & Rolled, Stabilized, Sensitized & 0.78 & \pm & 0.07 \\
\hline \multirow{4}{*}{3} & As Rolled & 0.87 & \pm & 0.01 \\
\hline & Rolled + Sensitized & 1.57 & \pm & 0.07 \\
\hline & Rolled + Stabilized & 1.12 & \pm & 0.12 \\
\hline & Rolled, Stabilized, Sensitized & 0.92 & \pm & 0.36 \\
\hline \multirow{4}{*}{4} & As Rolled & 1.25 & \pm & 0.12 \\
\hline & Rolled + Sensitized & 1.37 & \pm & 0.13 \\
\hline & Rolled + Stabilized & 1.21 & \pm & 0.07 \\
\hline & Rolled, Stabilized, Sensitized & 1.17 & \pm & 0.08 \\
\hline \multirow{4}{*}{5} & As Rolled & 1.46 & \pm & 0.07 \\
\hline & Rolled + Sensitized & 39.76 & \pm & 3.59 \\
\hline & Rolled + Stabilized & 1.13 & \pm & 0.12 \\
\hline & Rolled, Stabilized, Sensitized & 19.38 & \pm & 1.24 \\
\hline \multirow{4}{*}{6} & As Rolled & 1.64 & \pm & 0.21 \\
\hline & Rolled + Sensitized & 19.12 & \pm & 3.91 \\
\hline & Rolled + Stabilized & 1.42 & \pm & 0.14 \\
\hline & Rolled, Stabilized, Sensitized & 19.45 & \pm & 1.08 \\
\hline
\end{tabular}

